\title{
Power Situation in Oman and Prospects of Integrating Smart Grid Technologies
}

\author{
Marya Al Balushi* (D), Saif Al Omairi* iD and Kenneth E. Okedu** iD \\ *Department of Electrical and Communication Engineering, National University of Science and Technology, Muscat, PC 111, \\ Sultanate of Oman \\ (marya200560@nu.edu.om, saif200559@nu.edu.om, okedukenneth@nu.edu.om)
}

†Corresponding Author; okedukenneth@nu.edu.om or kenokedu@yahoo.com

Received: 25.02.2021 Accepted: 30.03.2021

\begin{abstract}
The sultanate of Oman maintained a stable growth in development of infrastructures in the last 50 years. Consequently, there is need for the electricity sector in Oman to keep pace with the resulting development, based on the size of the electricity network and the new technologies used in the different levels of the power system. This paper presents the current power situation in Oman, considering the prospects of the penetration of smart grid technologies with the national power grid. The paper gives an extensive review of Oman power system, with regards to the possible locations of solar and wind energy potentials. The roles of Information and Communication Technology (ICT), and the Data Management Scheme (DMS) in smart grid technologies were also presented with respect to the Oman national power grid. Furthermore, the topologies of energy sales and smart metering were considered as some of the salient benefits of the integration of smart grid technologies in the Sultanate power grid.
\end{abstract}

Keywords Smart grid, electricity network, Oman national grid, information technology, data management.

\section{Introduction}

In order to avoid the recent challenges in the use of fossil fuel, the need for the utilization of renewable energy sources is on the rise in most countries. Gulf Corporation Council (GCC) countries recently started to focus on the development of different organizations to handle research and development of renewable energy and related technologies. In UAE, Masder is the largest institute to develop and implement renewable energy projects in the GCC region [1]. The King Abdullah City for Atomic and Renewable Energy in the Kingdom of Saudi Arabia (KSA), and Qatar Environment and Energy Research Institute, are some of the other well-known renewable energy organizations in the this region. Though, the other GCC countries are working to develop renewable energy sector by supporting and encouraging research in their local universities [2]. The state of energy for the GCC region in 2017 shows that renewable energy accounts for 0.6 percent $(867 \mathrm{MW})$ of the total power capacity $(146 \mathrm{GW})$. The leading country is UAE with around 86 percent of the installed energy, then KSA comes in the second place by 16 percent, followed by Kuwait by 9 percent $[3,4]$.
Solar and wind energy are the most practical and economical type of renewable energy that are commonly employed in the GCC region. Some good numbers of solar and wind projects have been constructed in the GCC countries. In Qatar, KSA, UAE and Bahrain, several renewable projects have been launched. The Al Kharsaah photovoltaic (PV) $800 \mathrm{MW}$ solar power project was launched in 2018 in Qatar. Also, the KSA launched large solar and wind projects in 2018 with capacities of $300 \mathrm{MW}$ and $400 \mathrm{MW}$ respectively. UAE has huge renewable energy projects like $100 \mathrm{MW}$ project in Abu Dhabi, Dubai solar park with expected generating capacity of $5000 \mathrm{MW}$, to be commissioned in 2030 and wind farm project with $850 \mathrm{kWh}$ capacity in Sir Bani-Yas Island [5].

The population of Oman is estimated to be 5,175,047 as at 2020 [6]. The wide land area of Oman and the terrain nature enforced the power system to consist of four separated networks such as: Main Interconnected System (MIS), Dhofar Power System (DPS), Musandam power system and AD DUQM power system [7, 8]. The MIS covers around one million customers in Oman. It covers all the places in Oman except Dhofar, Musandam and AD DUQM, which has their own systems. In this paper, the main operating sections will 
be discussed for each power system; power generation, transmission and demand side. The MIS is in northern part of the country, DPS is in the southern part of Oman and the separated system in the rural areas. All these companies sell power to Oman Power and Water Procurements Company (OPWP). The power produced in the various systems is according to the demand request from the Oman transmission company based on the consumer requirements. The electricity demand in Oman has increased rapidly in the last few years with around 6\% in peak demand [9].

The location of Oman makes the country one of the most important energy corridors in the world. This is the drive that led the government and the private companies to invest in renewable energy projects, in order to generate power from wind and solar energy $[10,11]$. The solar energy density in Oman is among the highest in the world [12] and the wind data shows high potential for wind turbines in several parts of Oman.

Oman is facing several constrains in the electricity sector, due to the increase in electricity demand. The expected electricity demand will touch $8,960 \mathrm{MW}$ in 2023 as per OPWP report. Consequently, there would be huge financial cost of expanding generation, transmission and distribution networks. Another major issue is the fluctuation of the fossil fuel price, which affects the budget of the country, since it is solely oil dependent economy. Therefore, there is need to reduce the dependency on traditional generation methods of fossil fuel, that causes dangerous gas emissions to the atmosphere. According to the United Nations Climate Change program, Oman is subjected to reduce $2 \%$ of its carbon emission in 2030 [13]. One of the the way to overcome this challenge and to meet the target goal is by diversifying the power sources through the introduction of renewable energy systems [14].

The concept of integrating renewable energy sources into an electrical power distribution and transmission system is on the rise. The purpose of using this approach is to classify the economic, technical, regulatory and institutional barriers. Oman launched some renewable energy projects to reduce dependency on fossil fuels. The first project was solar power generation in Almazyounah with $303 \mathrm{~kW}$ capacity. Then the Dofar wind farm with about $50 \mathrm{MW}$. There are huge projects in solar power generation at planning stages, such as Ibri II project with $500 \mathrm{MW}, 100 \mathrm{MW}$ project planned in 2023 and the Petroleum Development Company of Oman (PDO) glass point project [15-17].

The Sultanate of Oman has been able during the last years to adopt many measures and incentives in the electricity sector, in order to enhance smart grid technologies and to gradually build the base rules of interconnection to the conventional power grid. The ongoing solar project of Ibri IPP with 500 MW capacity at $\$ 500$ million cost has shown the commitment to invest in power generation using solar photovoltaic system [18]. Ibri solar plant will be supplying the MIS by the end of 2021, with expected power supply to 33,000 homes with reduction of 340,000 tons per annum of $\mathrm{CO}_{2}$ emissions. In addition, Dhofar wind farm of a capacity of $50 \mathrm{MW}$ including $13 \mathrm{GE}$ wind turbines each with capacity of $3.8 \mathrm{MW}$ is another catalyst project in enhancing smart grid technology [19]. Dhofar wind farm was completed and connected to Dhofar power network in 2019. It has the capacity to meet the requirement of 16,000 homes and reduce carbon dioxide with a rate of 110,000 tons annually. Beside the solar PV and wind farm projects, with commercial scale adopted, there are standards for connecting small-scale solar PV generations into the grid, published in January 2017 by Authority for Electricity Regulation (AER) [20]. This will make the road map easy for customers to enhance the use of smart grids and allow distribution network to purchase electricity from roof-top of customers' PV system. Moreover, the sultanate of Oman decided that the greenhouse gas (GHG) emissions will be reduced by $2 \%$ by the year of 2030 by enhancing the integration of renewable energy. Also, by 2025 , intermix of $10 \%$ renewable energy will be in the electricity supply of Oman as approved by the Council of Financial Affairs and Energy Resources [21]. The change of fuel pricing policy played an important role in increasing the attention to renewable energy and smart grids technology in the Sultanate. The fuel pricing in Oman was reformed to accommodate the international fuel rate benchmark each month. Smart grid technology in Oman have been gradually enhanced through the incentive projects, renewable energy policies, pledged to reduce greenhouse gas (GHG) emissions and the effort to focus of the renewable energy resources.

Oman is one of the countries to increase communication and security systems for the smart grid, in order to receive quantum-safe encryption. In 2019, ABB upgraded the Oman Electricity and Transmission Company (OETC) Supervisory Control and Data Acquisition system (SCADA) with ABB's utility grade FOX615 multiplexer. In 2017, the Nama group announced the Automatic Meter Reading (AMR) plan, which will be done in cooperation with Centro Elettrotecnico Sperimentale Italiano) (CESI) Middle East Free Zone Establishment (FZE). This plan is targeting customers which consume more than $150 \mathrm{MWh}$. Some of the distribution companies have started installing digital meters in some places. Recently, the load dispatch centers in OETC is utilizing Wide Area Monitoring (WAN) system in order to boost up smart grid ICT [22]. The technology of smart grids involves high cyber-security and smart meters cyber protection. Fortunately, Oman is one of the leading countries in cyber-security $[23,24]$. To make the integration of smart grid easier, there is a list of exciting technologies which can be applied to a power grid for more reliability and smooth operation. In this paper, some important ICTs topologies will be discussed, in relation to the state of Oman national power grid and its preparation for smart grid operations.

In light of the above, this paper presents the current power situation in Oman and the prospects of smart grid technologies. Considering the size of the power network of Oman and high potential of renewable energy generation projects, there are huge prospects for the power system of Oman to use smart grid technologies in operating and controlling generation, transmission and distribution of its national power grid, by using smart systems such as smart meters; thus, encouraging consumers of electricity to go for smart home technologies. The rest of the paper is organized as follows; section 2 would give a brief about the power structure of Oman; section 3 gives the possible locations of 
wind and solar energy potentials in Oman. The integration of renewable energy in Oman is given in section 4, while the ICT topology in smart grids is presented in section 5. The application of DMS in smart grid with regards to the Omani power grid is presented in section 6 , while section 7 is about the analysis of energy sales and smart metering strategy in Oman power grid. Section 8 draws the conclusion of this paper.

\section{Power Structure of Oman}

\subsection{Main Interconnected System (MIS) in Oman}

Around one million customers exist in the MIS of Oman $[25,26]$. It covers most parts of Oman except, Dhofar which has its own system. The MIS includes three main operating sections: power generation, transmission and distribution. The MIS has eleven generation companies. The $(400 / 220 / 132 \mathrm{kV})$ power grid which is supervised and owned by OETC. Power is transmitted from the grid to the customers through the distribution companies. The first electricity distribution company is the Muscat Electricity Distribution Company (MEDC), feeding Muscat area. Another electricity distribution company is Mazoon Electricity Company (MZEC), feeding Al Dakiliya, Al Sharqiya and South AL Batinah, while Majan Electricity Company (MJEC), undertakes supply of electricity in the North Batinah, Al Dhahirah and Al Buraimi governorates, respectively. In addition, the MIS is connected to the power network of PDO and to the Abu-Dhabi power system in UAE and other members in GCC through Abu-Dhabi interconnection as shown in Fig. 1 [27]. The interconnection between the GCC countries is very important for the system security, it can be used in case of any emergencies and provide the energy supply. In addition, this interconnection may help in reducing the carbon emission by purchasing the power form other country which already used renewable energy instead of using crude oil.

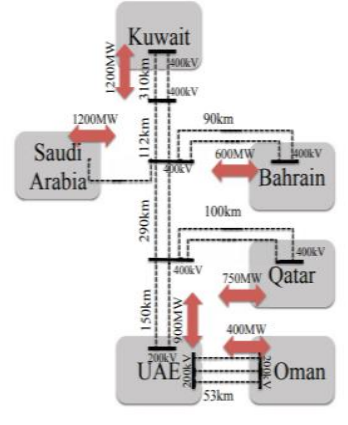

(a) Electricity map of the GCC Grid

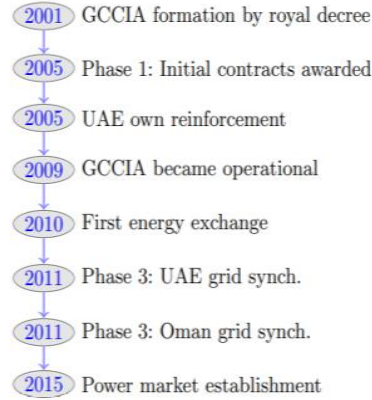

(b) GCCIA milestones.
Fig. 1. GCC interconnection grid overview

\subsubsection{Generation in MIS}

The contracted capacity for the existing power generation plants for MIS includes eleven plants as follows:
-Muscat governorate: Rusail Independent Power Project (IPP)

-Al Batinah south: Barka I Power \& Desalination Plant (ACWA), Barka II IPP (SMN) and Barka III IPP.

-North Al Batinah governorate: Sohar I Power \& Desalination Plant, Sohar II IPP and Sohar III IPP.

-Al Dhahirah governorate: Ibri IPP.

-Al Sharqiyah South governorate: Al Kamil and Sur IPPs.

-Al Dakhilya governorate: Manah IPP.

The details about the plants, year of installation and capacity are as follows [7]:

a. Rusail IPP

Rusail IPP plant is located in Al Rusail Industrial area. It has eight Frame 9E gas turbines which were installed between year $(1984-2000)$ and it operates in open-cycle. The gross site rating of the units varies between 82.3 MW and 96.9 MW. The total generation capacity of this power station is around 693.5 MW.

\section{b. Barka I Power \& Desalination Plant (ACWA)}

It was commissioned in 2003 and it consists of two Ansaldo V94.2 gas turbines with a capacity of $99.4 \mathrm{MW}$ and a steam turbine operating in combined cycle with a capacity of 198.7 MW. The total generation capacity of this power station is around 397.5 MW.

\section{c. Barka II IPP (SMN)}

Barka II IPP (SMN) was commissioned in 2009. It has three gas turbines with $122.8 \mathrm{MW}$ capacity for each one and two steam turbines with $160 \mathrm{MW}$ capacity for each. The total generation capacity of this power station is around 688.5 MW.

\section{d. Barka III IPP}

It was commissioned in 2012. It has two gas turbines with 247.5 MW capacity for each one and two steam turbines with $270.4 \mathrm{MW}$ capacity for each. The total generation capacity of this power station is around 765.5 MW.

\section{e. Sohar I Power \& Desalination Plant}

It has three Siemens V 94.2 gas turbines installed in 2006 and the capacity for each one is $125.7 \mathrm{MW}$. Also, it has one 
steam turbine with $220 \mathrm{MW} 4 \mathrm{MW}$ and four desalination units. The total generation capacity of this power station is around $597 \mathrm{MW}$.

\section{f. Sohar II IPP}

It was commissioned in 2012. It has two gas turbines with 247.5 MW capacity for each one and two steam turbines with 270.4 MW capacity for each. The total generation capacity of this power station is around $765.5 \mathrm{MW}$.

\section{g. Sohar III IPP}

It was commissioned in 2019. It has four gas turbines with 272.5 MW capacity for each one and two steam turbines with 327 MW capacity for the first and 326 MW capacity for the second. The total generation capacity of this power station is around 1743.1 MW.

\section{h. Ibri IPP}

It was commissioned in 2019. It has four gas turbines with 242.7 MW capacity each and two steam turbines with 285 MW capacity for the first and 286 MW capacity for the second. The total generation capacity of this power station is around 1541.7 MW.

\section{i. Al Kamil IPP}

It was commissioned in 2002. It has three GE PG9171E gas turbines with 97.1 MW capacity for each one and its operating in open cycle. The total generation capacity of this power station is around 291.4 MW.

\section{j. Sur IPP}

It was commissioned in 2014. It has five gas turbines with 248.6 MW capacity for each one and three steam turbines with 310 MW capacity for the first and 155 MW capacity for the second. The total generation capacity of this power station is around 2018.2 MW.

\section{k. Manah IPP}

It is the first IPP in Oman, it was commissioned in 1996. This plant consists of three GE PG6541B gas turbines with 27 MW capacity for each one and two GE PG9171E gas turbines with 91.1 MW each. In 2020, OPWP, cancelled the GE PG6541B gas turbine, in order to replace it with new gas turbines GT2A \&GT2B with 182.2 MW capacity for each one.

\subsubsection{Transmission in MIS}

OETC is responsible for the transmission side around Oman and covering all MIS areas. As shown in Fig. 2 [26], in the
MIS, the voltage levels for transmission operation are $400 \mathrm{kV}, 220 \mathrm{kV}$ and $132 \mathrm{kV}$. Figure 3 [28] shows the overhead and underground length used by Main Interconnected Transmission System (MITS) at the end of 2019. While Fig. 4 [29], shows the transformer capacity which is used by MITS.

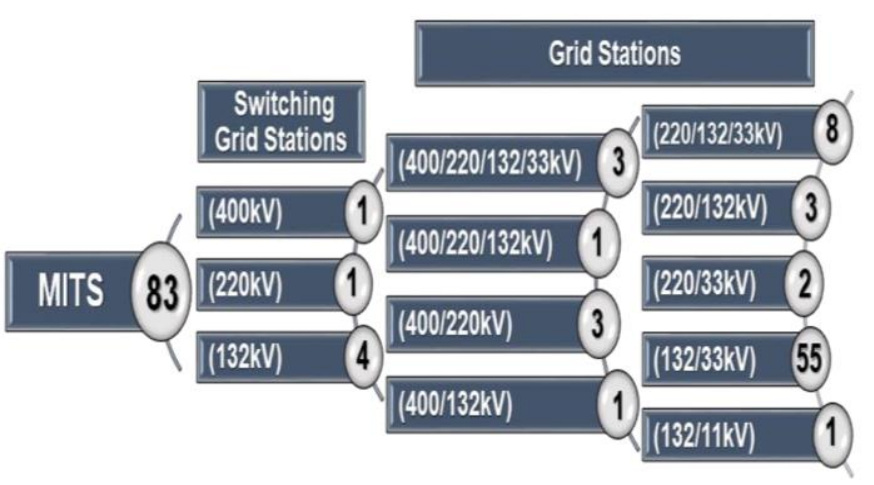

Fig. 2. Number of grid stations in MITS.

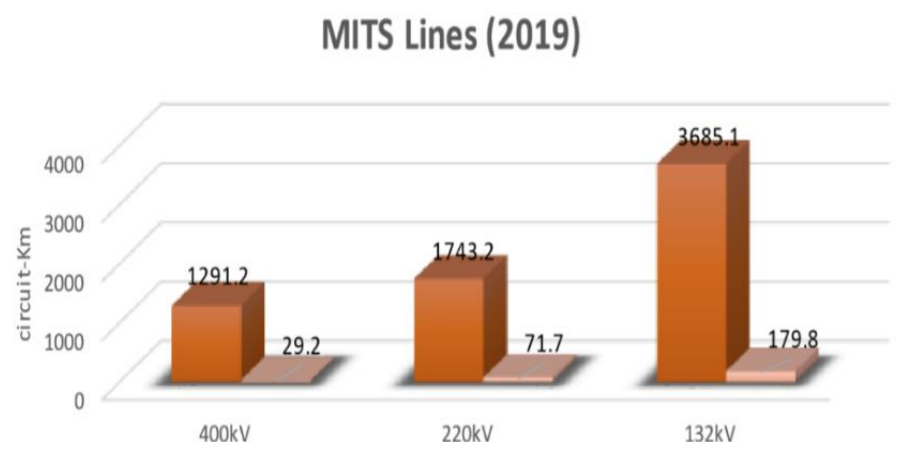

Fig. 3. OHL \& UGC lengths (circuit $/ \mathrm{km}$ ) at MITS by end of 2019.

\section{MITS Transformers Capacity (2019)}

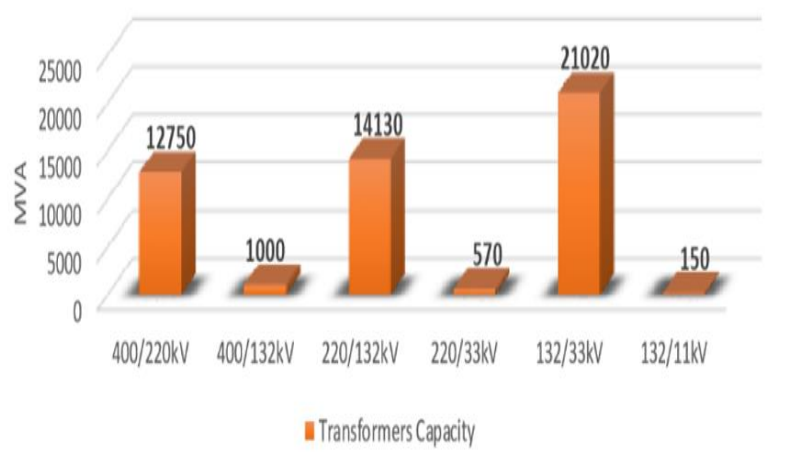

Fig. 4. Transformers capacity (MVA) at MITS by end of 2019 . 


\subsubsection{MIS Demand}

The maximum power demand usually increases in the summer during high temperature especially in the following months: May, June and July. The 24 hours demand for MIS transmission system is shown in Fig. 5 [29], where it is obvious that the maximum demand in MIS power system appears in the early hours of morning and afternoon. The highest peak demand recorded in 2019 MIS peak load was 6539.75 MW.

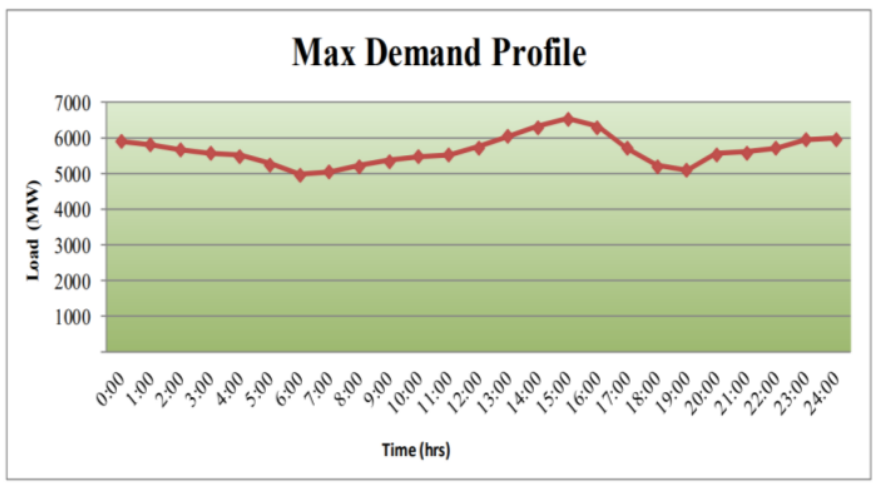

Fig. 5. MIS load on Peak day-2019

On the other hand, the minimum demand of power usually occurs in winter periods with the lowest temperature, especially in the following months: December and January. The 24 hours minimum demand for MIS transmission system is shown in Fig. 6.

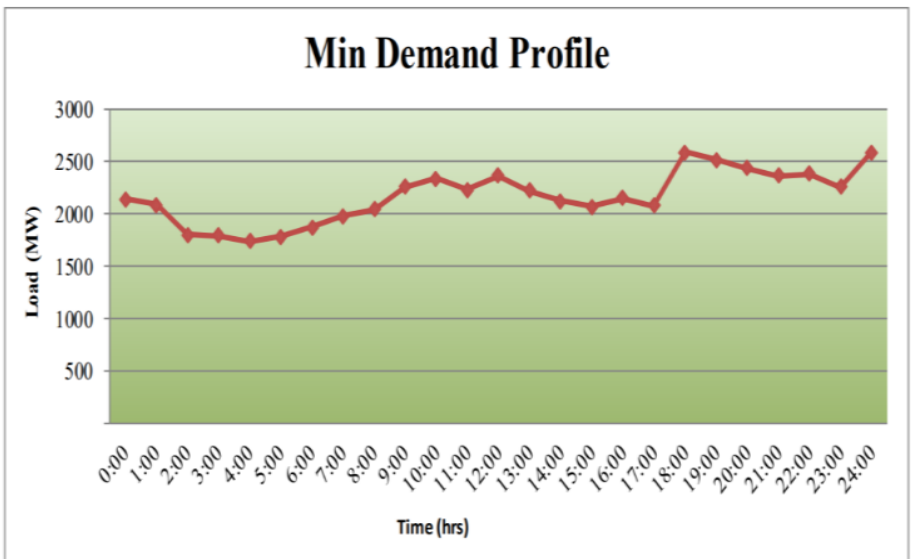

Fig. 6. MIS load on low demand day

\subsection{Dhofar Power System (DPS):}

\subsubsection{Generation in DPS}

This power system covers all of Dhofar governorate and supplies around 110,063 customers [28]. It has three parts including: four generation companies, $132 \mathrm{kV}$ grid which is owned and operated by OETC and DPS. The DPS act as its own distribution company, distributing and supplying power to customers in the region. In addition, the DPS is connected to PDO power system via $132 \mathrm{kV}$. There is a study under consideration for an expansion of interconnection capacity of the $400 \mathrm{kV}$ North-South. It has four generation companies, three are gas-based plant and one is a renewable energy plant. The sub systems of the DPS generation units are:

\section{a. Salalah Power \& Desalination Plant}

It was commissioned in 2010. It has five gas turbines with 56.2 MW capacity each and two steam turbines with $82 \mathrm{MW}$ capacity each. The total generation capacity of this power plant is around $445 \mathrm{MW}$.

\section{b. Salalah II IPP}

It was installed in 2018, and has five gas turbines with 69 MW capacity each and two steam turbines with $84 \mathrm{MW}$ capacity each. The total generation capacity of this power plant is around $444 \mathrm{MW}$.

\section{c. New Power Station (NPS)}

It was installed in 2002, and has eight gas turbines working in open cycle with capacity between 19.8 MW to $37 \mathrm{MW}$ each. The total generation capacity of this power plant is around 272.9 MW.

\section{d. Dhofar Wind Farm}

This is the first renewable energy plant that was commissioned in 2019. It has 13 turbines with capacity 3.85 MW each. The total generation capacity for this power plant is $50 \mathrm{MW}$.

\subsubsection{Transmission in DPS}

OETC is responsible for the transmission side in Dhofar area. As shown in Fig. 7 [26], the voltage level for transmission operation in this area is only $132 \mathrm{kV}$.

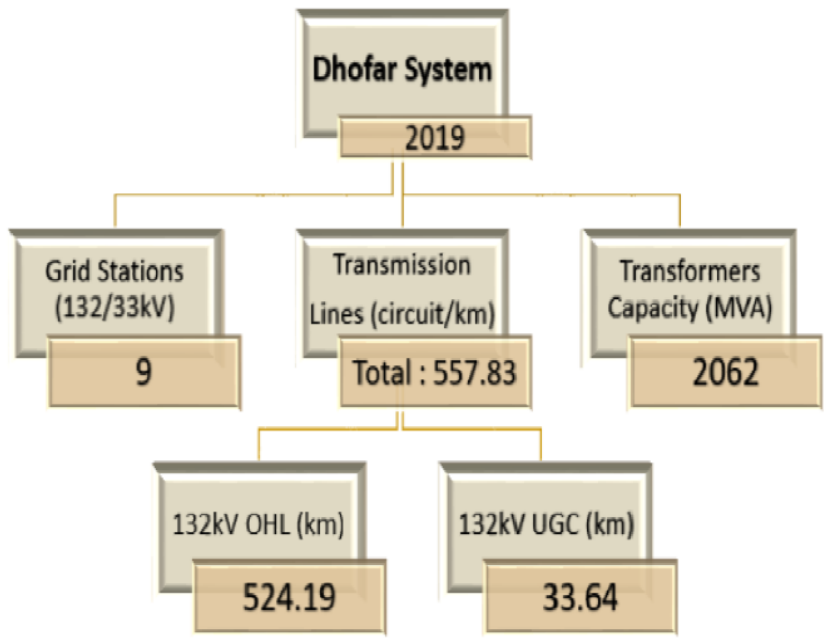

Fig. 7. Number of grid stations in Dhofar 


\subsubsection{Demand in DPS}

The peak load demand profile during 24 hours for DPS is shown in Fig. 8. It is obvious that the maximum demand in DPS power system appears in the early hours of morning and afternoon. The highest peak demand recorded by OETC load dispatch center in 2019 was 6539.75 MW [7]. On other hand, the minimum demand of power usually occurs in the winter, during cold weather. The 24 hours minimum demand for DPS transmission system is shown in Fig. 9 [29].

\section{Max Demand Profile}

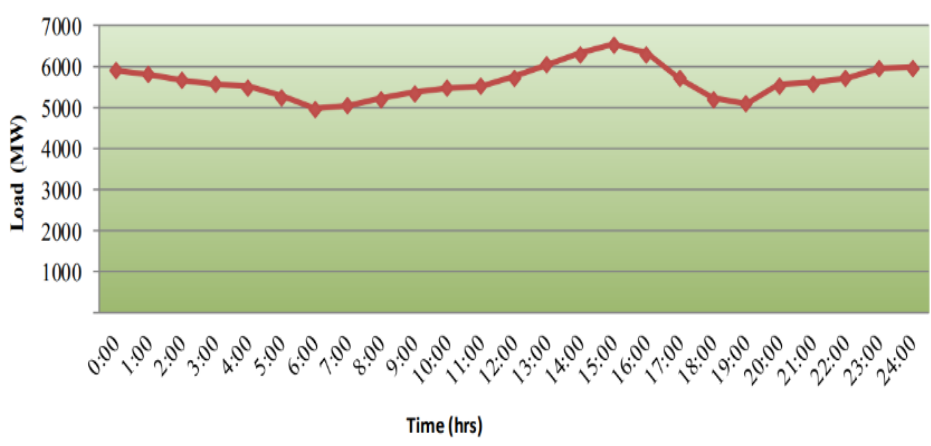

Fig. 8. DPS load on Peak day-2019

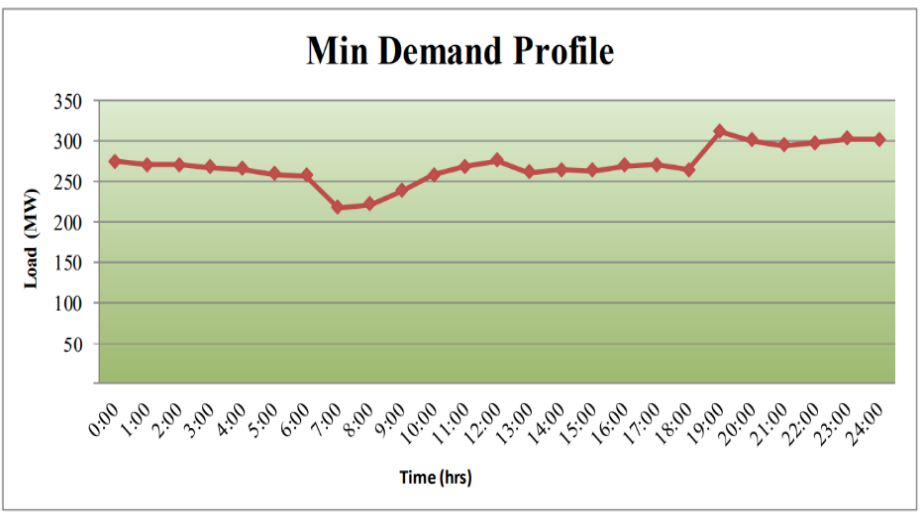

Fig. 9. DPS load on low demand day

\subsection{Musandam Power System.}

Musandam governorate is located in the northern region of Oman and it separated by UAE. It has population of around 45,155, and it is expected to increase in the coming years. Due to its location, Musandam has a separate electricity power system which is operated and own by Rural Areas Electricity Company (RAECO).

The type of generators used in RAECO is diesel-fired generators with capacity around $83 \mathrm{MW}$. Musandam IPP was added in 2017, and it uses natural gas as fuel with capacity of 123 MW. As shown in Fig. 10, the power demand is of two cases: the peak and minimum demands.

\subsection{AD DUQM Power System.}

AD DUQM is located in the Al Wusta governate, the eastern region of Oman. It has a population of around 11,269

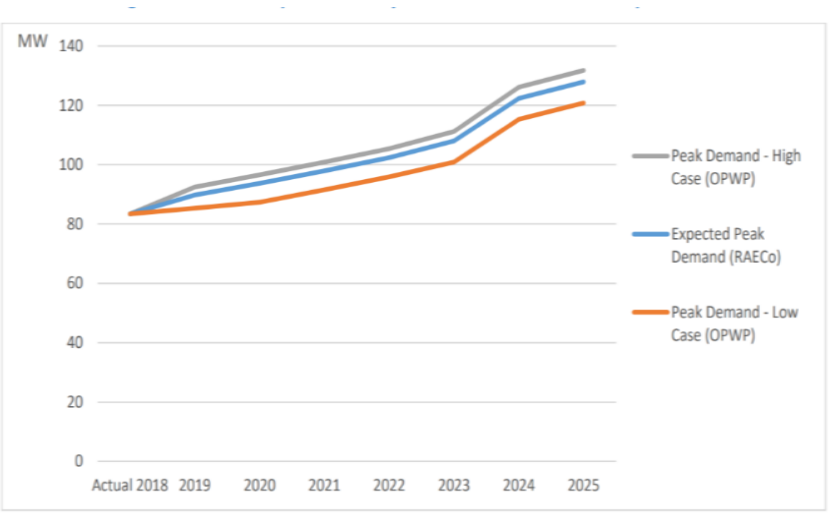

Fig. 10. Musandam power demand

- this is expected to be done in the year 2023.

There is only one power station covering this area and it is operated and owned by RAECO. It consists of a diesel-fired generator with capacity around $67 \mathrm{MW}$. As shown in Fig. 11, the power demand is in two cases: the peak and minimum demands.

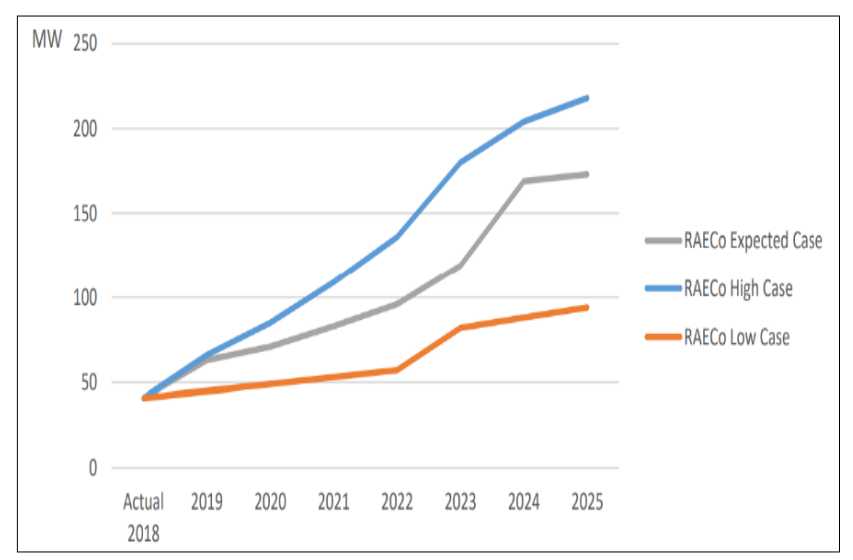

Fig. 11. AD DUQM power demand

and it is expected to increase in the future [28]. Due to its location, AD DUQM power system is operated by RAECO. Though OETC is planning to integrate this area with MIS, -

\subsection{Benefits of the MITS}

OETC $220 \mathrm{kV}$ transmission system at MITS is connected with GCC power grids (Bahrain, Saudi Arabia, Kuwait, UAE and Qatar) through UAE at Mahada grid station as shown in Fig. 1. The target from this interconnection is to increase the security of electricity supply within the GCC. Also, this MITS is interconnected with Sohar Aluminum 220kV busbar. The transfered power between them can be up to $300 \mathrm{MW}$. In addition, this MITS is connected to PDO $132 \mathrm{kV}$ through overhead line-single circuit (between Nizwa in OETC system and Nahadah in PDO system). The wind farm in Dhofar which is connected 
to OETC transmission system is interconnected to PDO network at $132 \mathrm{kV}$.

\section{Possible Locations of Solar and Wind Energy Potential in Oman}

The location of sultanate of Oman is between latitudes 40, 16, 20 and 26 north and between longitudes 50, 51, 40 and 59 degrees east [30]. This location in the southeastern part of the Arabian Peninsula on the tropic of cancer overlooks three essential water bodies which are; the Gulf of Oman, the sea of Oman and the Arabian sea; thus, making Oman one of the most important energy corridors in the world.

The total land area of Oman is $309,500 \mathrm{~km}^{2}(119,499$ sq. miles) with population density of 16 per $\mathrm{km}^{2}$ (43 people per $\mathrm{mi}^{2}$ ). This ensures the existence of large areas for use in building solar or wind power plants. As shown in Fig. 12, the coastline from Ras Musandam to Ras Darbat Ali of 3,165 km $(1,967 \mathrm{mi})$ provides an important factor of the geographical location, the view to the Indian ocean and the costal wind [30].

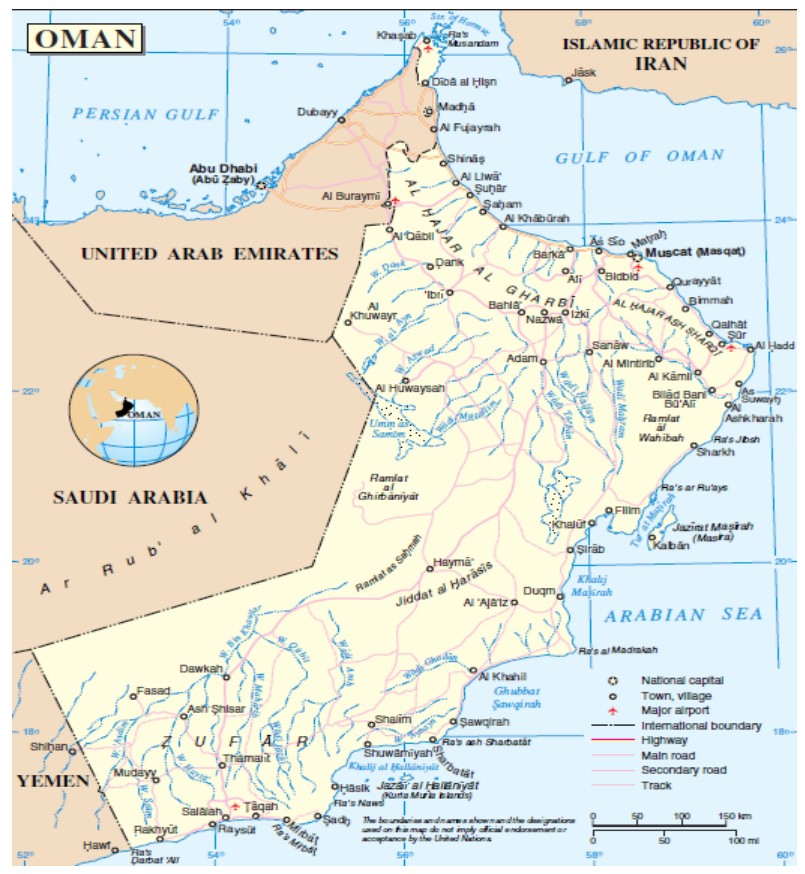

Fig. 12. Sultanate of Oman Map [31].

The climate of Oman is subtropical dry and hot in general with low annual rain fall. The monthly average temperature for the 24-year period 1986-2009 shown in Fig. 13 indicates that the temperature in January is between $16.7^{\circ} \mathrm{C}$ and $25.1^{\circ} \mathrm{C}$ in contrast to the temperature in June of $40.0^{\circ} \mathrm{C}$. Based on the Geographic Information System (GIS), the solar radiation maps indicate that the potential of solar energy is very high during the whole year on most parts of Oman. This is due to the geographic location as well as the ratio of sky clearance [32], which is 342 days per year. The direct normal irradiation map of Oman shows that the longterm average of Direct Normal Irradiation (DNI) considering the period between 1999 and 2018 varies between 5.2 $\mathrm{kWh} / \mathrm{m}^{2}$ and $6.8 \mathrm{kWh} / \mathrm{m}^{2}$ daily. Moreover, the long-term average of DNI varies between $1,899 \mathrm{kWh} / \mathrm{m}^{2}$ and 2,483 $\mathrm{kWh} / \mathrm{m}^{2}$ yearly. Nevertheless, to provide a clearer picture of solar energy potential, the theoretical potential should be taken into account, which identify the long-term energy availability of solar resource at any location. The Global Horizontal Irradiation (GHI) is the sum of direct and diffuse irradiation components received by a horizontal surface and it is the variable that illustrates the theoretical potential. The GHI map of Oman shows that the GHI is reaching high values in southern part of Oman and averaged around 6.1 $\mathrm{kWh} / \mathrm{m}^{2}$ in the northern part of Oman. These values of DNI and GHI indicate the high potential of solar energy in Oman [31]. In addition, the PVOUT map of Oman indicates considerably high PV power output potential on most parts of Oman as shown in Fig. 14. PVOUT represents the amount of power generated per unit of the installed PV capacity over the long-term, and it is measured in kilowatt hour per installed kilowatt-peak of the system capacity $(\mathrm{kWh} / \mathrm{kWp})$, which is between $30.3^{\circ} \mathrm{C}$ and $40^{\circ} \mathrm{C}$.

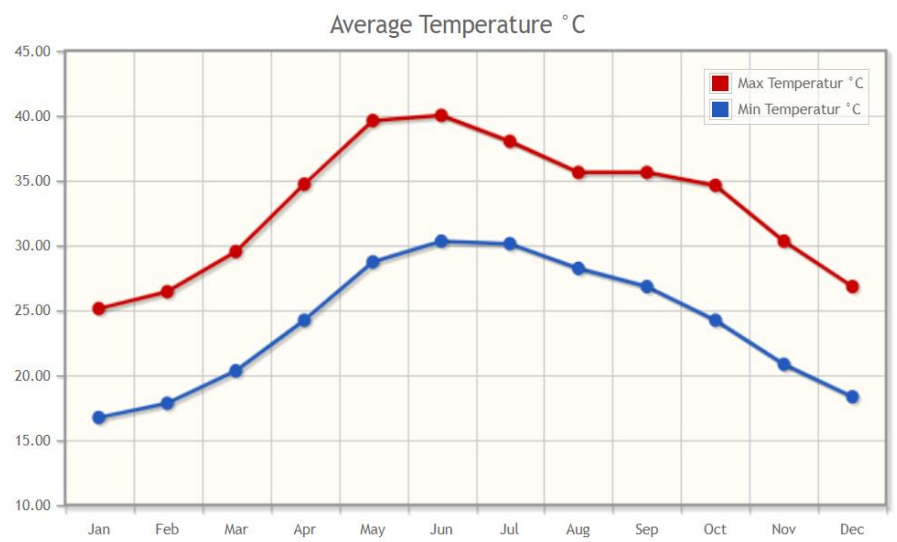

Fig. 13. Monthly averages temperature for the 24-year period

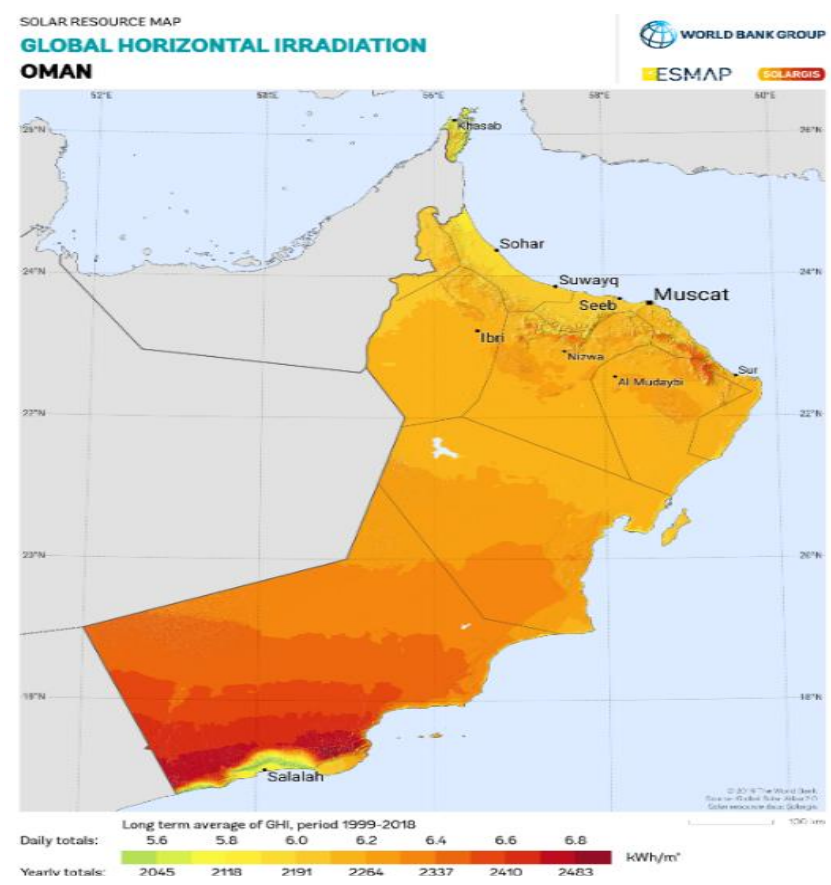

(a) Global Irradiation in Oman 


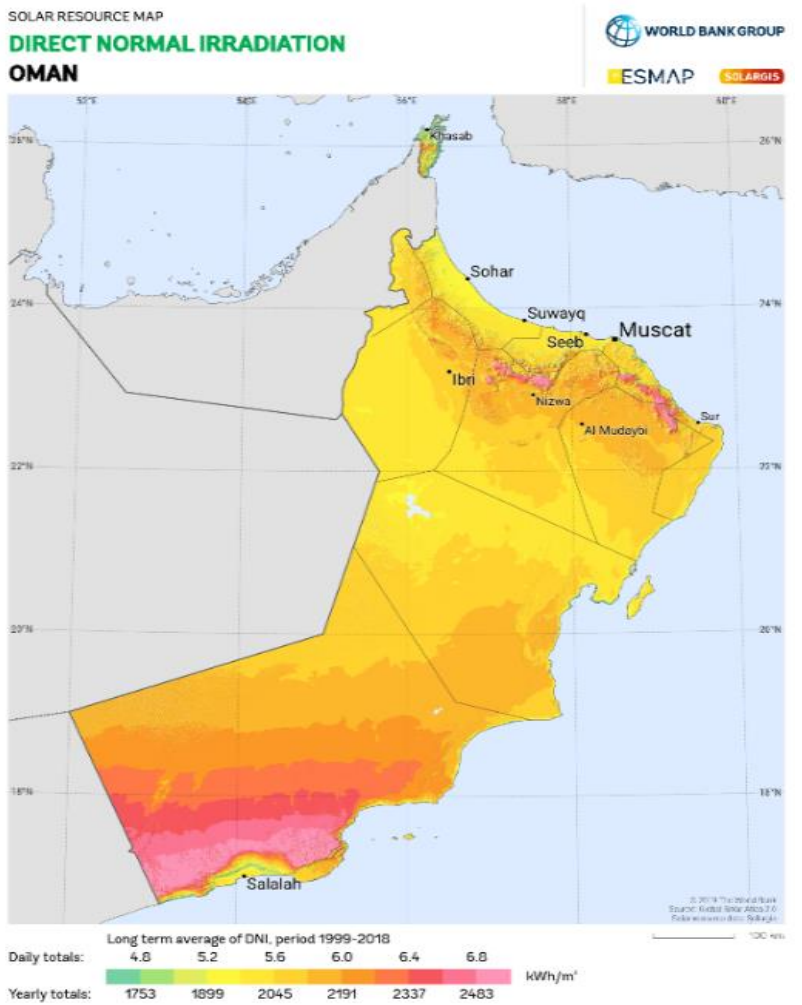

(b) Direct Irradiation in Oman.

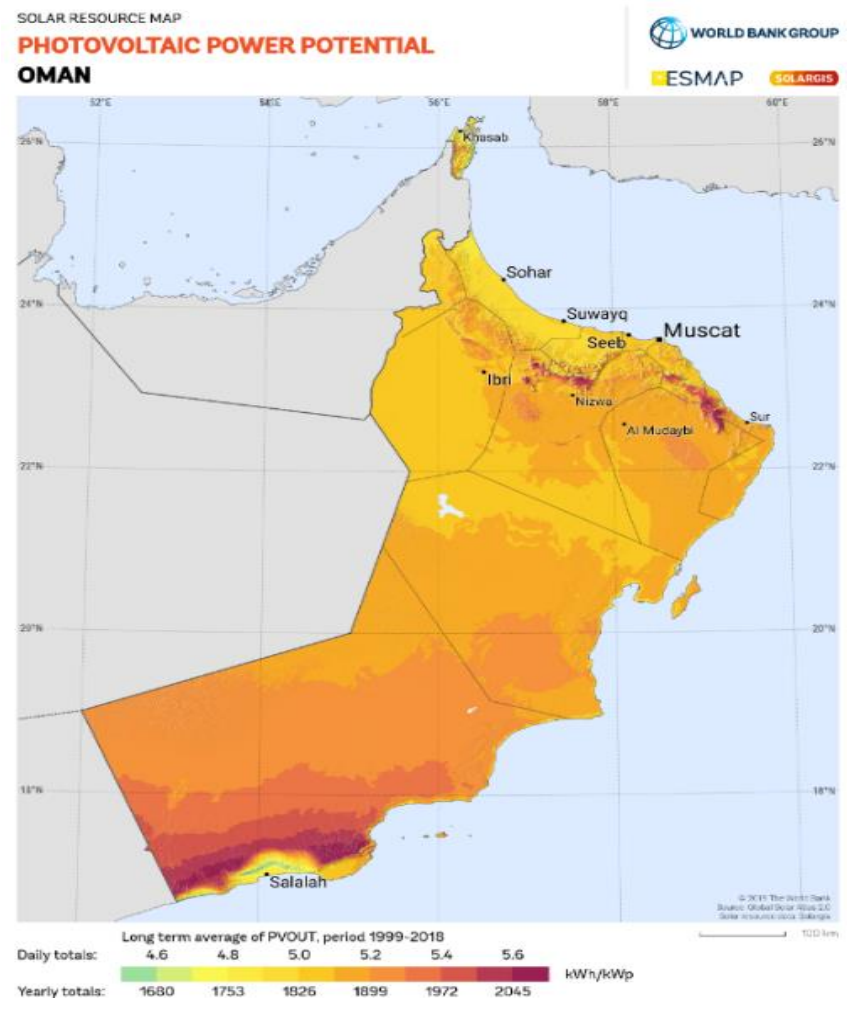

(c) Photovoltaic potential in Oman

Fig. 14. PVOUT maps of Oman.
Analyzing the average daily global radiation and sunshine duration of 25 different locations in Oman indicate that the maximum radiation is in Marmul with $6 \mathrm{kWh} / \mathrm{m}^{2} /$ day and the minimum is in Sur with $4.2 \mathrm{kWh} / \mathrm{m}^{2} /$ day [11]. The average radiation in the 25 locations is more than 5 $\mathrm{kWh} / \mathrm{m}^{2} /$ day. As shown in Fig. 15, the sunshine (hours/day) data shows that it is almost more than 8 hours/day [32].

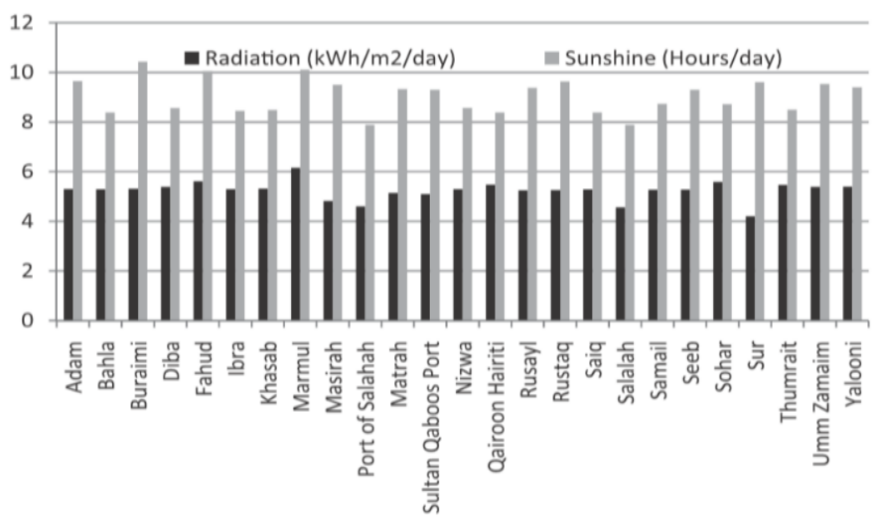

Fig. 15. Average daily global radiation and sunshine duration.

All of these data emphasize high potential of solar energy on most parts of Oman. In 2008 AER in Oman emphasized this in the renewable energy resources of Oman study [33]. It was mentioned that the solar energy density in Oman is among the highest in the world. Among the successful projects for using solar energy in Oman is PDO Amin PV project, which has a capacity of 100 Megawatts [34]. Amin IPP is in northeast of Salalah $300 \mathrm{~km}$ far and providing power to PDO's interior operations. Amin IPP is covering $4 \mathrm{~km}^{2}$ area, producing power sufficient to supply 15,000 houses and saving 95.5 million $\mathrm{m}^{3}$ of natural gas annually [35]. In addition, Amin IPP reduces 225000 tons of $\mathrm{CO}_{2}$ emission annually which is equivalent to the emission of 23,000 cars. Moreover, due to the optimal location of Oman that makes it in the world energy corridor, Oman invested in one of the largest utility-scale solar PV IPPs. This project is Ibri-2 IPP, which has the capacity of $500 \mathrm{MW}$, that is enough to supply power to around 33,000 homes and reduces 340,000 tons of carbon dioxide emissions annually [36].

Based on the global wind Atlas, it is clear from Fig. 16 that, the wind speed of Oman at $10 \mathrm{~m}$ is higher in middle part and southern coastal line. The data of the wind speed is the critical key for identifying the possible location of wind energy potential. In addition, the availability of wind power and economic availability of the conversion system are also the main factors that provide a clear evidence for the potential of wind energy.

In the sultanate of Oman there are more than 31 meteorology stations where different weather parameters are recorded. Hence wind parameters such as maximum, minimum and average wind speed as well as wind direction are recorded, including other parameters like visibility, rain, pressure and humidity. Based on a wind power potential 
study in Oman in 2010, considering 27 different locations (south, north, and the middle part of Oman), the potential of wind energy in Oman is high. The most promising locations are Thumrait, Qairoon Hairiti, Masirah and Sur. Figure 17 shows the wind speed at $10 \mathrm{~m}$ and $80 \mathrm{~m}$ in Thumrait, Qairoon Hairiti, Masirah, Joba and Sur. The average wind speed in the five locations at $10 \mathrm{~m}$ is around $5.7 \mathrm{~m} / \mathrm{s}$ and around 7.7 $\mathrm{m} / \mathrm{s}$ at $80 \mathrm{~m} \mathrm{[36]}$.

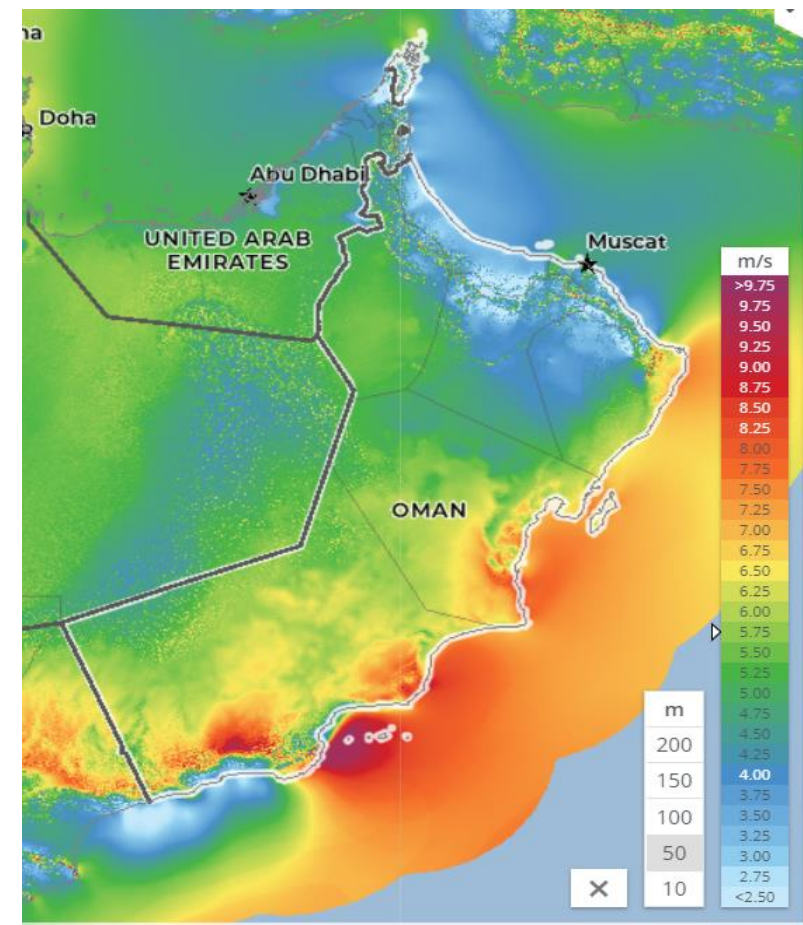

Fig. 16. Wind speed in Oman.

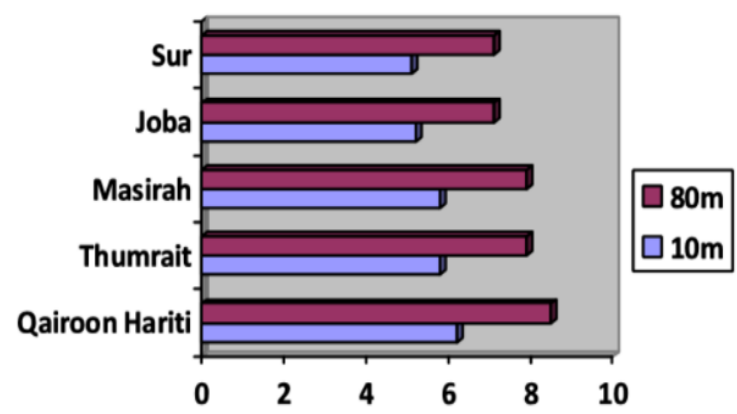

Fig. 17. Wind speed in Oman at $10 \mathrm{~m}$ and $80 \mathrm{~m}$

Table 1 shows the cost of energy for wind power generation for 27 locations in Oman. The cost of energy is $0.088 \$ / \mathrm{kWh}, 0.092 \$ / \mathrm{kWh}, 0.101 \$ / \mathrm{kWh}$ and $0.117 \$ / \mathrm{kWh}$ in Thumrait, Qairoon Hairiti, Masirah and Sur respectively [37]. This cost of energy is obtained using $1500 \mathrm{~kW}$ wind turbine.
Table 1. Cost of energy of wind power generation in Oman.

\begin{tabular}{|c|c|c|c|c|c|c|c|c|}
\hline Location & $\begin{array}{c}\mathrm{kWh} \\
(2 \mathrm{MW})\end{array}$ & $\begin{array}{c}\cos t / k W h \\
(\$)\end{array}$ & $\begin{array}{c}\mathrm{kWh} \\
(1.5 \mathrm{MW})\end{array}$ & $\begin{array}{c}\cos t / k W h \\
(\$)\end{array}$ & $\begin{array}{c}\mathrm{kWh} \\
(850 \mathrm{~kW})\end{array}$ & $\begin{array}{c}\cos t / k W h \\
(\$)\end{array}$ & $\begin{array}{c}\mathrm{kWh} \\
(250 \mathrm{~kW})\end{array}$ & $\begin{array}{c}\operatorname{cost} / \mathrm{kWh} \\
(\$)\end{array}$ \\
\hline Thumrait & 43849910 & 0.080 & 35963460 & 0.074 & 18792440 & 0.084 & 5275875.7 & 0.088 \\
\hline Qairon Hariti & 43327020 & 0.081 & 35916519 & 0.075 & 18481970 & 0.085 & 5071149.5 & 0.092 \\
\hline Masirah & 38924870 & 0.090 & 32340512 & 0.083 & 16736550 & 0.094 & 4603766.5 & 0.101 \\
\hline Sur & 33105240 & 0.106 & 27103316 & 0.099 & 14326840 & 0.110 & 3989092.3 & 0.117 \\
\hline Joba & 23019430 & 0.152 & 19120362 & 0.140 & 9878090 & 0.159 & 2729290.4 & 0.171 \\
\hline Marmul & 21545120 & 0.162 & 17902263 & 0.150 & 9460520 & 0.166 & 2525296 & 0.185 \\
\hline Dugm & 21528130 & 0.162 & 17823371 & 0.150 & 9170000 & 0.171 & 2576420.7 & 0.181 \\
\hline Qurn Alam & 18333550 & 0.191 & 15269994 & 0.175 & 8132090 & 0.193 & 2147324.8 & 0.217 \\
\hline Jabal shams & 14848880 & 0.235 & 12266499 & 0.218 & 6493520 & 0.242 & 1757819.1 & 0.265 \\
\hline Fahoud & 13588470 & 0.257 & 11315752 & 0.237 & 5998190 & 0.262 & 1596966.2 & 0.292 \\
\hline Ras AlHadd & 12858780 & 0.272 & 10690774 & 0.251 & 5472560 & 0.287 & 1526251.1 & 0.305 \\
\hline Yalloni & 12323700 & 0.284 & 10290594 & 0.260 & 5353340 & 0.294 & 1436039.6 & 0.324 \\
\hline Qalhat & 10186180 & 0.343 & 8495884 & 0.315 & 4651880 & 0.338 & 1196889.2 & 0.389 \\
\hline Salalah & 10131800 & 0.345 & 8498380 & 0.315 & 4768740 & 0.330 & 1171406.1 & 0.398 \\
\hline Burami & 6208290 & 0.563 & 5274791 & 0.508 & 3181640 & 0.494 & 719688.2 & 0.647 \\
\hline Saiq & 5462220 & 0.640 & 4601421 & 0.582 & 2675330 & 0.588 & 633114.9 & 0.736 \\
\hline Diba & 5434480 & 0.643 & 4549098 & 0.589 & 2619880 & 0.600 & 637123 & 0.731 \\
\hline Muscat & 5338280 & 0.655 & 4515192 & 0.593 & 2664730 & 0.590 & 618569.1 & 0.753 \\
\hline Sohar & 4739740 & 0.737 & 4052082 & 0.661 & 2452860 & 0.641 & 553461.5 & 0.842 \\
\hline Adam & 4454350 & 0.785 & 3758278 & 0.713 & 2178860 & 0.722 & 512524 & 0.909 \\
\hline Khasab port & 3807420 & 0.918 & 3219409 & 0.832 & 1888160 & 0.833 & 441309.5 & 1.056 \\
\hline Nizwa & 3590500 & 0.973 & 3026272 & 0.885 & 1735580 & 0.906 & 422287.6 & 1.103 \\
\hline Mina-Salalah & 3211830 & 1.088 & 2697223 & 0.993 & 1605680 & 0.979 & 377543.7 & 1.234 \\
\hline Samial & 2505770 & 1.395 & 2156295 & 1.242 & 1431970 & 1.098 & 297964.4 & 1.564 \\
\hline Ibra & 2322090 & 1.505 & 1993985 & 1.344 & 1315010 & 1.196 & 275302 & 1.692 \\
\hline Bahla & 1185390 & 2.948 & 1014282 & 2.641 & 733250 & 2.145 & 141219.2 & 3.299 \\
\hline Rustaq & 853570 & 4.094 & 733766 & 3.651 & 612140 & 2.569 & 109290.2 & 4.263 \\
\hline
\end{tabular}

RAECO identified a map for potential sites that are suitable for setting up wind energy projects as shown in Fig. 18 [38].

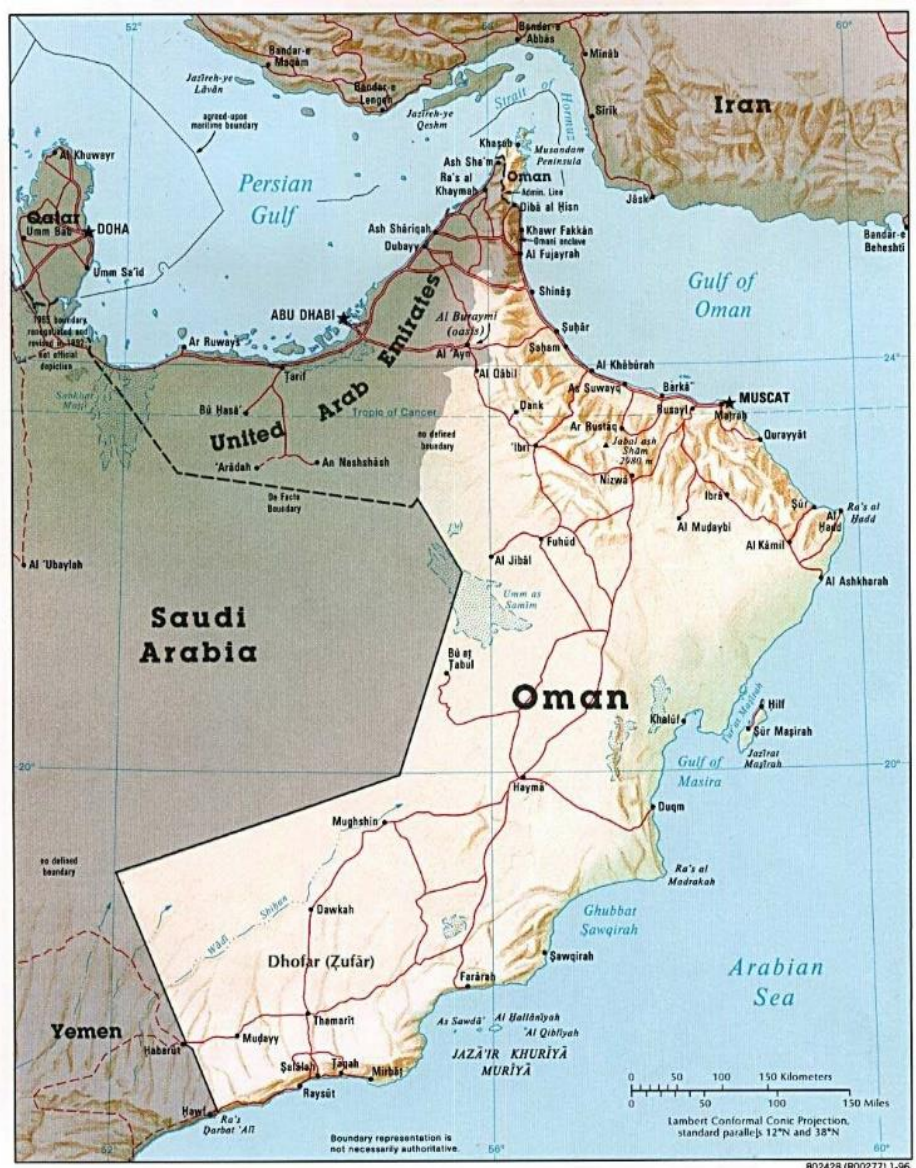

Fig. 18. Potential of suitable sites for setting up wind energy projects. 
In the last years, there were different projects for utilizing wind energy, however, the $50 \mathrm{MW}$ wind farm project in Dhofar is the latest and biggest project in Oman. The wind farm site is located approximately $100 \mathrm{~km}$ northeast of Salalah in the area known as Fatkhit, north of Salalah in the governorate of Dhofar. Dhofar wind farm project is developed by Masdar Institute. The wind farm consists of 13 wind turbines developed by GE, each with an electricity generation capacity of 3.8 MW and it was completed in 2019 [39]. The successful completion of this project considering the capacity and utility size, could foster the investment in wind energy generation.

\section{Integration of Renewable Energy Sources}

The purpose of using the system approach of renewable energy integration is to classify the economic, technical, regulatory and institutional barriers. Also, this integration topology is applicable to business models for incorporating smart grid technologies into power grid operations, capacity planning and demand-side management [40].

The points below show the benefits of integrating renewable sources into power grids:

- It will reduce carbon emissions $\mathrm{CO}_{2}$.

- It helps to reduce the cost of electricity and reduce peak load by increasing the assets use through integration of distributed systems and customer loads.

- It helps to achieve the standards for renewable energy.

- It reduces oil consumption by using Plug in Electric Vehicles (PHEV) operations in the grid.

- It will ensure the security and reliability from microgrid applications in highly constrained and protected areas of the electric grid.

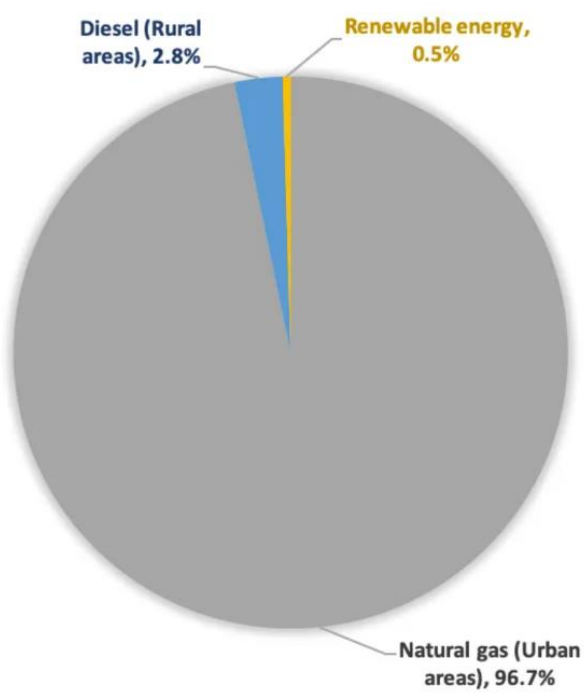

Fig. 19. Types and share of fuel used for electricity generation in Oman
As shown in Fig. 19, the percentage of renewable energy contribution in electric generation for Oman is only $0.5 \%$. On other hand, $96.7 \%$ is for natural gas, which is the main fuel and the rest $2.8 \%$ for diesel [41]. The plan for year 2025 is to increase the renewable energy contribution to be $10 \%$.

\subsection{Dhofar Wind Power Integration in Oman}

This wind project is located in Dhofar with capacity of $50 \mathrm{MW}$. As shown in Fig. 20, the wind farm consists of 13 x 3.83 MW wind turbines connected into the $132 / 33 \mathrm{kV}$ substation which is located between Thumrait (Dhofar) and Harwail (PDO) [42].

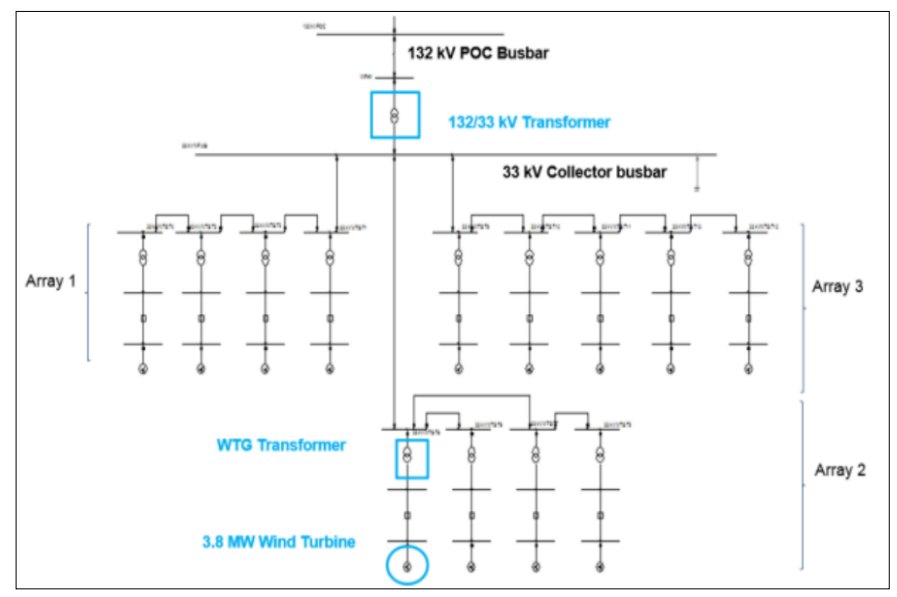

Fig. 20. Dhofar wind farm layout.

In order to connect the existing circuit to the new substation, the topology must be line-in/line-out circuit. It will act as the Point of Connection (POC) as shown in Fig. 21. The $33 \mathrm{kV}$ Air Insulated Switchgear (AIS) substation is connected to $132 \mathrm{kV}$ substation through a transformer with the following specifications: 63 MVA 132/33 kV, on-load tap changer.

The $33 \mathrm{kV}$ AIS substation has three feeders: one of them have five wind turbines. While, the remaining two feeders have four wind turbines each. For each wind turbine there is a $33 \mathrm{kV}$ switchgear, each one has 4.8 MVA $33 / 6 \mathrm{kV}$ transformer.

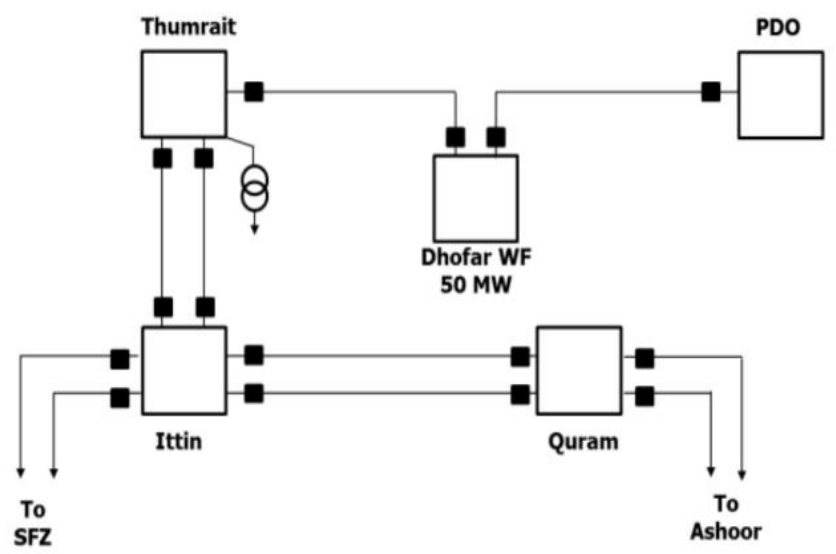

Fig. 21. Dhofar wind farm substation [20]. 


\section{A. Wind Speed Measurement}

In order to prepare for the new project, the wind speed measurement was conducted for five months in periods from 29th May 2017-18th October 2017. The data were collected from the anemometers located in Dhofar wind farm, and the wind-MW curve was presented.

\section{B. Dynamic Analysis}

The study of the dynamic performance for the $50 \mathrm{MW}$ wind farm can be achieved by analyzing its behavior during or after any fault which happened on the power system. So, the wind farm should sustain and keep connected to the network. The place which was taken as a reference for the possibility of three phase fault is the POC. This indicates that the voltage must be at least $90 \%$ of its pre-fault nominal voltage. This is a requirement for all wind farms in any transmission system.

\section{Power Flow Intermittency Analysis}

The operation of wind turbine depends on many factors such as: wind speeds, air density, and turbine characteristics. If the wind speed is low; less than $2.5 \mathrm{~m} / \mathrm{s}$, the turbine will not be able to produce electricity. On the other hand, if the wind speed is more than $25 \mathrm{~m} / \mathrm{s}$, which is very high, the turbine must be stopped or it will be damaged. So, the wind speed effects the power output.

The Quasi-dynamic simulation was conducted with the response shown in Fig. 22 [42], in order to study the impact of wind on both load flow and network performance. The purpose of this analysis is to ensure that generators can adapt with the power changes due to wind speed variations and to ensure zero MW transfer between Dhofar \& Harwail (132 kV interconnection).

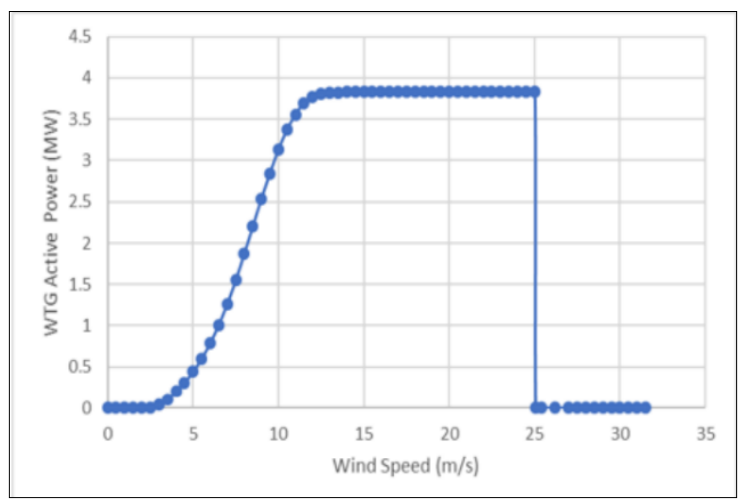

Fig. 22. Active power vs steady wind speed.

\section{Technologies for Smart Grid}

\subsection{Energy storage system}

There are multiple types of energy storage such as: electrochemical (fuel cells and batteries), electromechanical (pump hydro, flywheels and compressed air), electromagnetic (superconducting magnetic storage) and electrostatic (ultra-capacitors). Figure 23 shows a typical application of energy storage system in a smart grid [23, 43]. The energy management from energy storage in smart grids, will make the power grid gain more stability and reliability. Some of the benefits from using energy storage are:

- Works to mitigate the fluctuations of renewable energy (wind, solar)

- Increase the breakthrough level of solar and wind in smart grid

- Manage the load shifting by using the energy stored in off-peak time in the peak demand of load.

- Improvement in power quality by smoothing the voltage.

- Regulate frequency in both transmission and distribution.

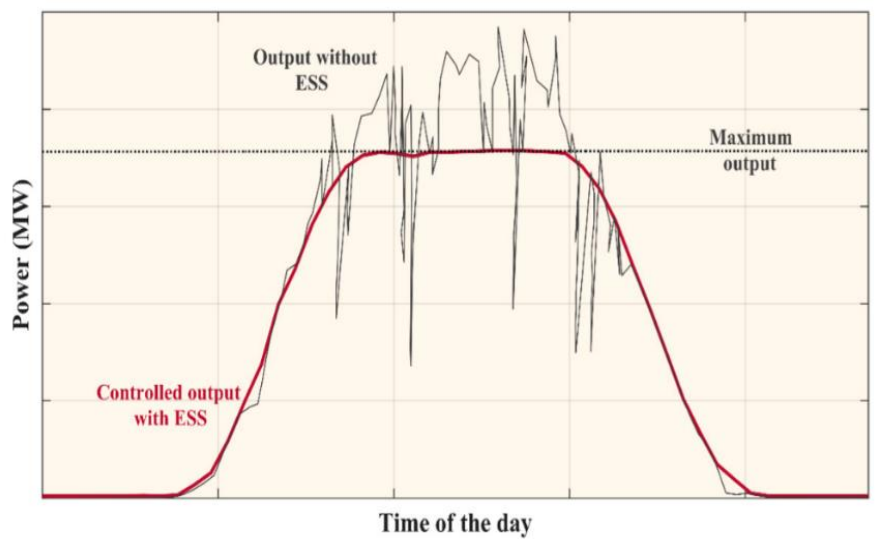

Fig. 23. Power output of renewable energy sources with and without energy storage system

\subsection{Telecommunication systems}

The conventional power system is using SCADA with the following communication methods; wireless radio connection, dial up lines, IP protocol and Ethernet. But, in smart grids, the scenario is different than conventional power system. The smart grid contains a big amount of data which require communication system with high level of quality, in order to ensure security, and privacy. Below are the communication techniques expected to be used in smart grids and their benefits:

\section{a. Wireless Communication:}

$\checkmark$ Cost effective for installation

$\checkmark$ Remote applications

$\checkmark$ Speedy placement

b. Satellite Communication:

$\checkmark$ Coverage ability

$\checkmark$ Speedy placement

c. Microwave communication:

$\checkmark$ Reliable for point-to-point communication because of secured data exchange at large bandwidth. 
Figure 24, shows the telecommunication network. The wired communication is possible choice and can be used in smart grids for optical fiber and power line communication.

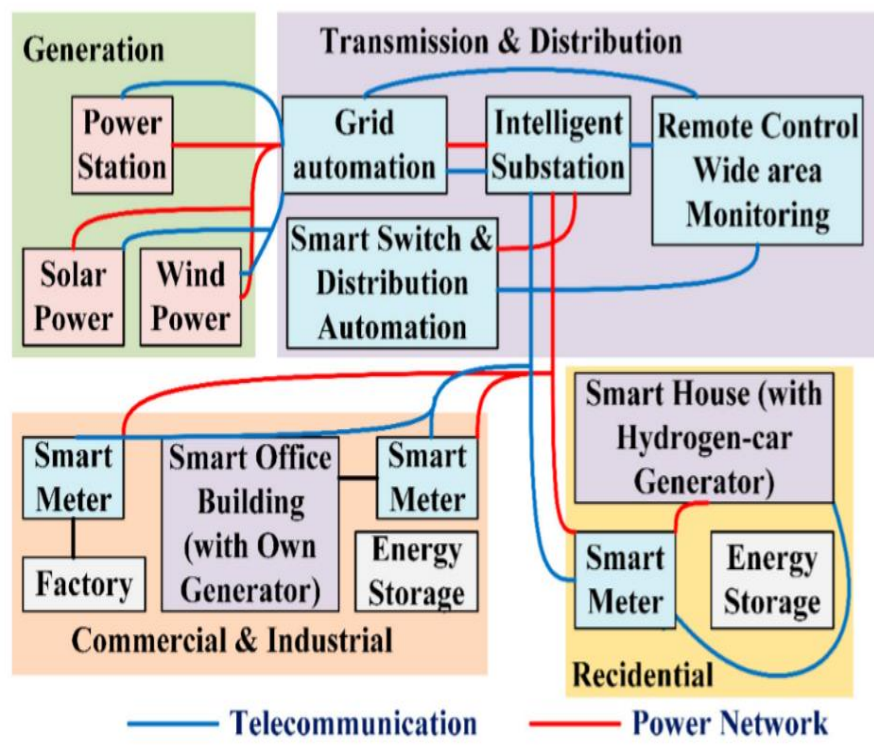

Fig. 24. Telecommunication technology in smart grids.

\subsection{ICT Infrastructure for Advance Protection System}

The ICT infrastructure is integrated in smart grids in order to respond to grid faults, protect the system from any cyber-attack and keep the system flexible. The consequences of getting attacks are disclosing customers account information, delay in information transmission and making the network inaccessible. Figure 25 [35] shows the ICT infrastructure in smart grids, consisting of intelligent and electricity delivery layers.

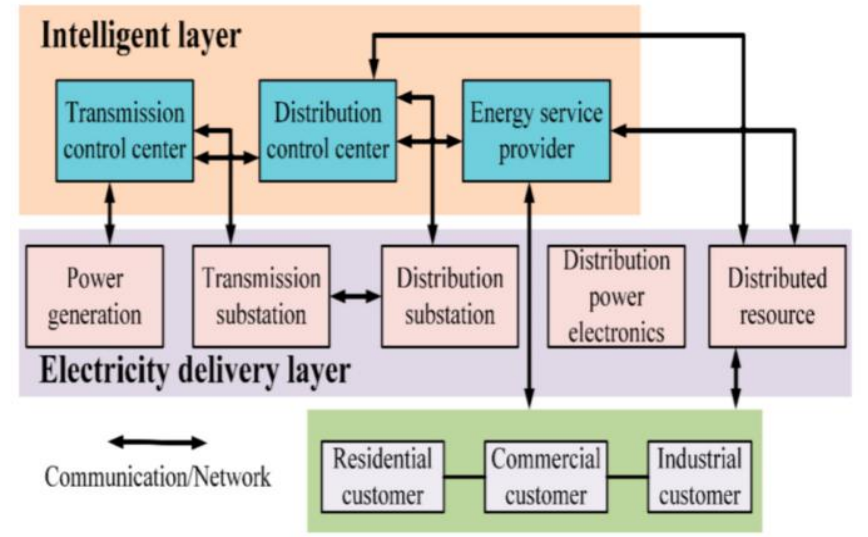

Fig. 25. ICT infrastructure in smart grids.

\subsection{Data Management Scheme (DMS) in Oman National Grid}

Oman electrical sector is divided into four isolated parts: the MIS covering the northern area, DPS for Dhofar governorate, PDO power system in central Oman, and rural power system which covers Musandam, Al Wusta, Dhofar (excluding DPS areas) and some parts of the Dakhilia governorates located in south east. Among all of these three areas (excluding PDO power system) there are three categories of the companies: generation, transmission and distribution. All the companies of these categories are supervised by the Authority for Public Services Regulation (APSR) [44]. There are several power generations companies and four main distribution companies as earlier mentioned: MEDC, MJEC, MZEC and Dhofar Power. However, OETC is the significant channel between the generation and distribution. It owns and operates transmission networks of the MIS as well as Dhofar power system. OETC also plays a vital role in balancing the generation and demand to maintain optimal power dispatch of power in Oman. It operates $132 \mathrm{kV}$ and above with 83 grid station in MIS and 9 in Dhofar system.

As a consequence of the vital role of OETC in power transmission and power dispatch in Oman, the company centralized the data management facility in order to operate, coordinate and manage the dispatch activities in Oman national grid. This is the Load Dispatch Center (LDC) which consists of three main different facilities: main control center at Mawalleh, back up control center that is under construction at a different location and a regional control center at Salalah to manage the activities of Dhofar area.

The operation of LDC consist of five main tasks to manage the energy transmission system in OETC as shown in Fig. 26. The main task is load dispatch considering balancing the load system on a real time basis with the power generation. This includes also the load forecasting, generation, maintenance, planning, scheduling of power and water dispatch and dispatch instructions. The second task of LDC is coordinating all the operations in the transmission system from the first step of planning until the final actual operation as well as the maintenance and contingencies handling during the operation of the transmission system. The third task is including all the activities of the communication and SCADA such as planning, implementation and maintenance of communication and computer infrastructure, which facilitates the above functions of operational coordination and dispatch. The fourth and fifth tasks are issuing the system performance reports and energy settlement reports [45].

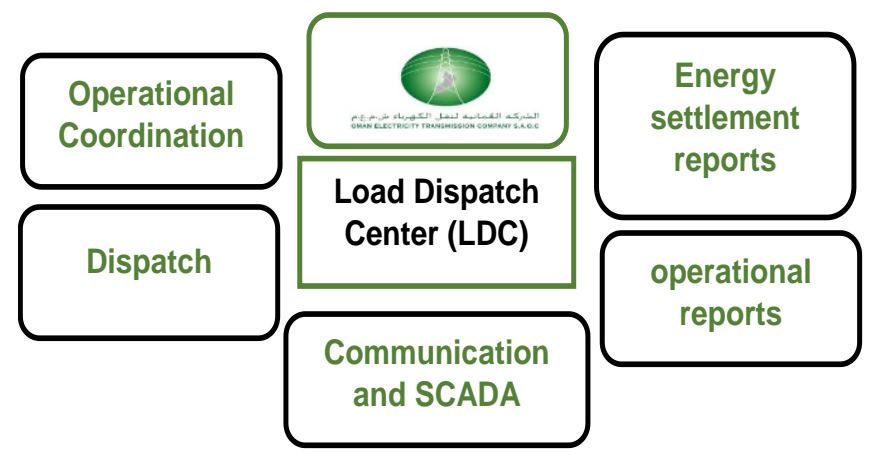

Fig. 26. Load dispatch center tasks.

In the load dispatch center in Mawalih (OETC head office), 83 grid stations are connected through substation control systems with remote terminal units, using the IEC 
60870-5-101 communication protocol [46]. In addition, MEDC, MZEC and MJEC control centers are interconnected with the LDC. On the other hand, 8 grid stations are connected to the control center of Dhofar power system. There are three softwares used in both control center: SCADA, Energy Reporting and Data Sharing (ERDS) and DIgSILENT power factory. SCADA and ERDS are integrated to provide a cost-effective tool for monitoring and controlling the transmission system. DIgSILENT power factory is used for planning, operation and power system protection studies as well as conducting load flow report of the system.

SCADA retrieves the reading data and alarms from the grid stations and has the ability to control the devices or machines of the grid stations to manage the flow of power in the transmission system as required. Simultaneously, the ERDS software provides real time decision making according to the data reading of SCADA and also analyze the data to provide a clear view of the transmission system- -performance information to the power control engineers. ERDS software [47] is a customized metering data system which is used for data collection from the automatic meters reading at the substations via various communication protocols over Optical Ground Wire (OPGW) and other different media, that enables meter data gained on a continuous basis. The software is customized to provide Web Login for OETC and the distribution companies for reporting and analysis of meter data using graphical trends as shown in the Fig. 27.

Figure 28 shows the SCADA data flow chart starting from the substation to the control center. From the end devices, IED's (Meters-Relays), Distributed Control System (DCS) and transducer, the data is collected by the Remote Terminal Units (RTU), Programmable Logic Controller (PLC) and DCS and sent to the SCADA server through the communication channels and then the data is processed using the ERDS and the power flow application [48]. This procedure of operation using SCADA system provides an effective tool to control and manage the transmission system and Oman national grid optimally.

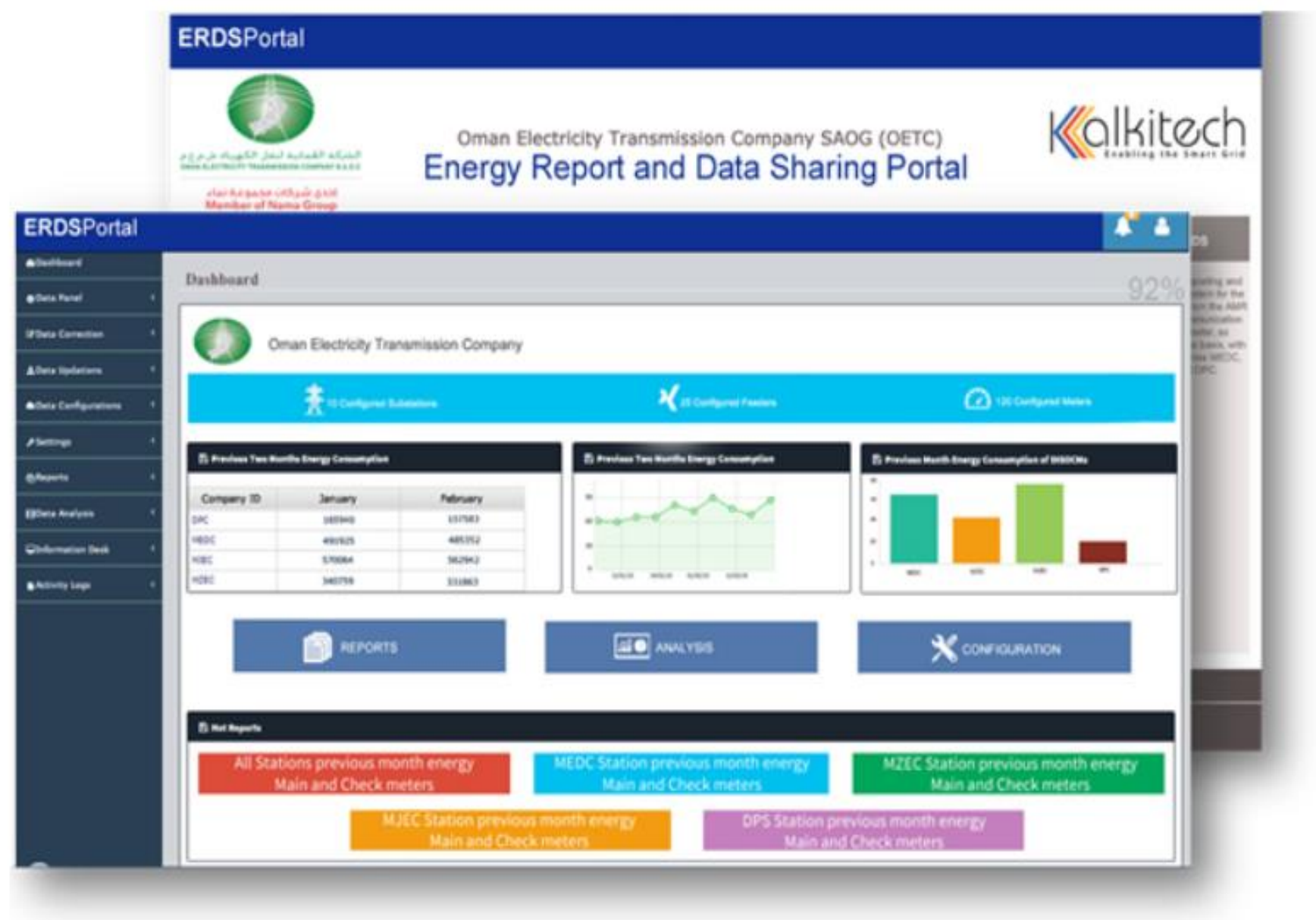

Fig. 27. Energy reporting and data sharing software. 


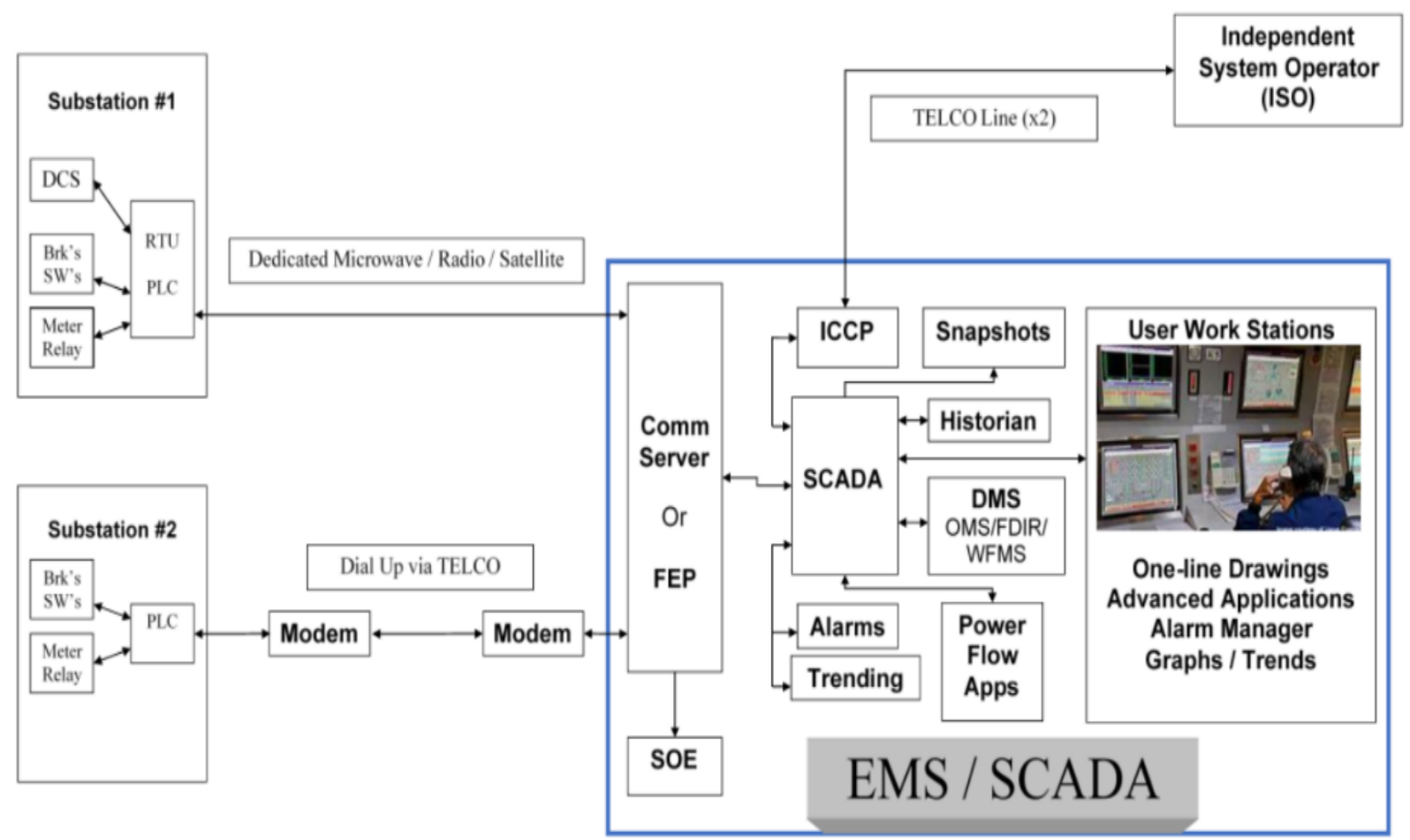

Fig. 28. SCADA Scheme and data flow chart [49]

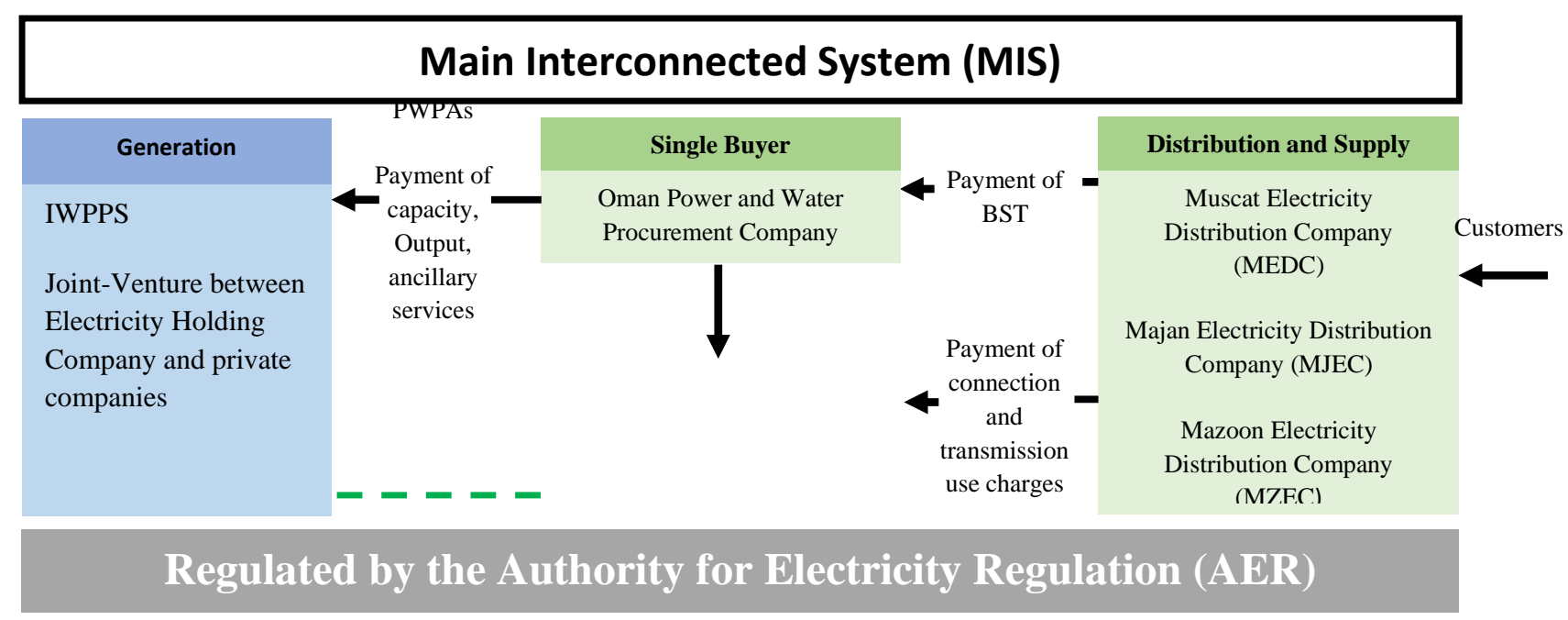

Entities wholly owned by Nama Group

Denotes direction of payments

Fig. 29. Main Interconnected system. 


\section{Energy Sales and Smart Metering}

The electricity market in Oman follow the procedure as shown in the following figures. OPWP is the single buyer in all the systems (MIS, Dhofar, Rural networks) (Figs. 29-31), which pays for the generation companies and the transmission company (OETC). OPWP is currently a monopolistic bulk buyer and seller of Oman's electricity and associated desalinated water. It is a wholly-owned subsidiary of Nama Group. As indicated in Fig. 30, the payment directory goes from the customers to the distribtution companies and from the distribution companies to OPWP. Only in the rural system, the generation, transmission and distribution are operated by rural area electricity company (TANWEER).
The authority for public services regulation issued the tariff for electricity into two categories: residential tariffs and commercial tariffs. The residential tariffs consist of two sections: the citizens account tariff and additional accounts tariff as shown in Table 2. The citizens account tariff starts from $15 \mathrm{Baisa} / \mathrm{kW}$ within the range of $0-2000 \mathrm{kWh}$ per month and increased to $20 \mathrm{Baisa} / \mathrm{kW}$ in the range of 2001$4000 \mathrm{kWh}$ per month and also increased to $30 \mathrm{Baisa} / \mathrm{kW}$, if the consumption is more than $4000 \mathrm{kWh}$ per month. For the residential additional accounts, the tariff structure starts from the range of $0-500 \mathrm{kWh}$ per month with $20 \mathrm{Baisa} / \mathrm{kW}$ and it reaches the maximum tariff of 30 Baisa $/ \mathrm{kW}$, if the consumption is more than $1500 \mathrm{kWh}$ per month [50].

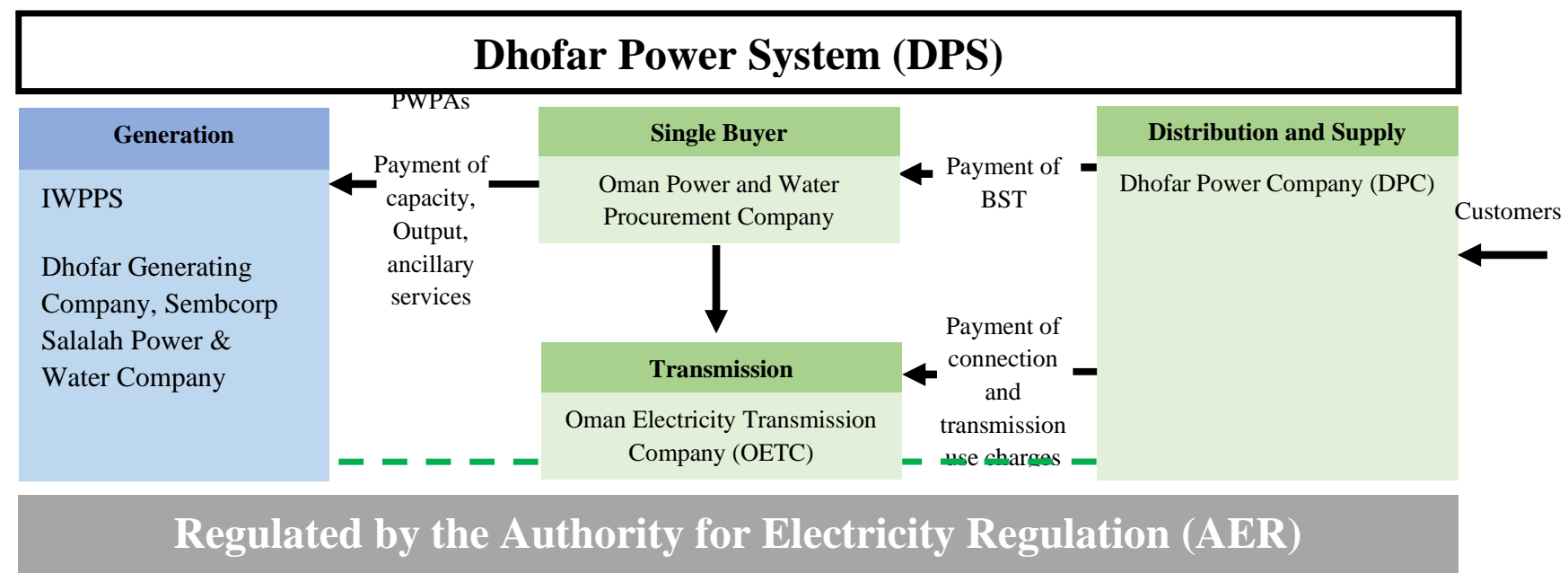

Privatized entities, partially owned by Nama Group

Entities wholly owned by Nama Group

$\longleftarrow$ Denotes direction of payments

Fig. 30. Dhofar power system.

\section{Rural Systems - Rural Areas Electricity Company}

\begin{tabular}{|c|}
\hline Generation \\
\hline $\begin{array}{c}\text { RAEC's Own } \\
\text { generation }\end{array}$ \\
\hline IPP's \\
\hline
\end{tabular}
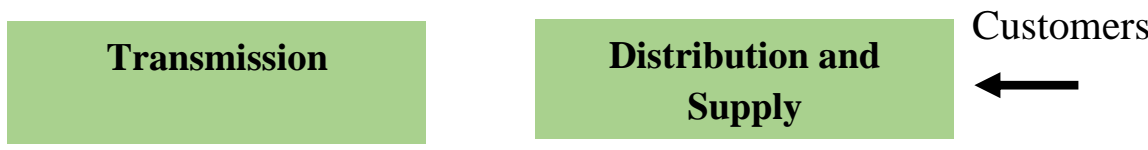

\section{Regulated by the Authority for Electricity Regulation (AER)}

Privatized entities, partially owned by Nama Group

Entities wholly owned by Nama Group

Denotes direction of payments

Fig. 31. Rural system. 
Table 2. Tariff structure for citizens' accounts and additional accounts.

\begin{tabular}{c|c|c}
\hline Category & $\begin{array}{l}\text { Tariff Structure } \\
(\mathbf{k W h} / \text { Month) }\end{array}$ & Tariff (Baisa/kW) \\
\hline \multirow{3}{*}{ Citizen's account } & $0-2000$ & 15 \\
\cline { 2 - 3 } & $2001-4000$ & 20 \\
\cline { 2 - 3 } & More than 4000 & 30 \\
\hline \multirow{2}{*}{$\begin{array}{c}\text { Residential and } \\
\text { additional } \\
\text { accounts }\end{array}$} & $0-500$ & 20 \\
\cline { 2 - 3 } & $501-1500$ & 25 \\
\cline { 2 - 3 } & More than 1500 & 30 \\
\hline
\end{tabular}

The commercial tariffs is consist of three different sections: large customers, non-residential customers and agriculture and fisheries customers, as shown in Table 3. Non-residential customers follow two different tariffs: winter tariffs with 21 Baisa/kW and summer tariffs with 29 Baisa $/ \mathrm{kW}$. The agriculture and fisheries customers follow three different ranges of tariffs: 0-500 kWh/month, 501-1500 $\mathrm{kWh} /$ month and more than $1500 \mathrm{kWh} /$ month with 20 Baisa/kW, 25 Baisa/kW and 30 Baisa/kW, respectively [51].

Table 3. Commercial tariff structure.

\begin{tabular}{c|c|c}
\hline Category & Tariff Structure (kWh/Month) & $\begin{array}{l}\text { Tariff } \\
(\text { Baisa/kW) }\end{array}$ \\
\hline $\begin{array}{c}\text { Large } \\
\text { Customers }\end{array}$ & CRT \\
\hline & $\begin{array}{l}\text { Winter Tariff (From the first of } \\
\text { January to the end of April) } \\
\text { (From the first of October until } \\
\text { Non- } \\
\text { Residential }\end{array}$ & 21 \\
\cline { 2 - 3 } & $\begin{array}{l}\text { Summer Tariff (from the first of } \\
\text { May until the end of September) }\end{array}$ & 29 \\
\hline Agriculture \\
$\begin{array}{c}\text { and } \\
\text { Fisheries }\end{array}$ & 0-3000 & 12 \\
\cline { 2 - 3 } & Mo01-6000 & 16 \\
\hline
\end{tabular}

Authority for public services regulation specified that large customers must follow the Cost Reflective Tariff (CRT). Hence large customers should pay the total cost of electricity consumption without government subsidy. It includes the cost of electricity generation, transmission, distribution \& supply to the customer. The CRT tariff targets

\section{RS-232 serial cable \\ Modem side: RJ45 / RJ11 connector \\ Meter side: RJ11 connector}

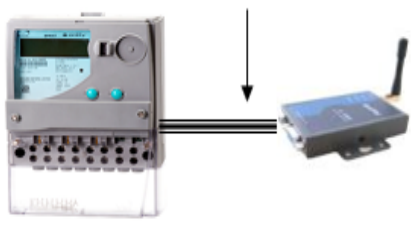

Meter Requirements RS-232 port for AMR Command set documentation for developing AMR application
- the customers with consumption more than $150 \mathrm{MWh}$ in a year. The cost of energy is the summation of the following elements:

Total cost $=$ bulk supply charge + transmission charge + distribution system charge + supply charges

All the customers following CRT tariffs should be using digital meters shown in Fig. 32, with automated meter reading facility which is capable of reading the meter consumptions on hourly basis.
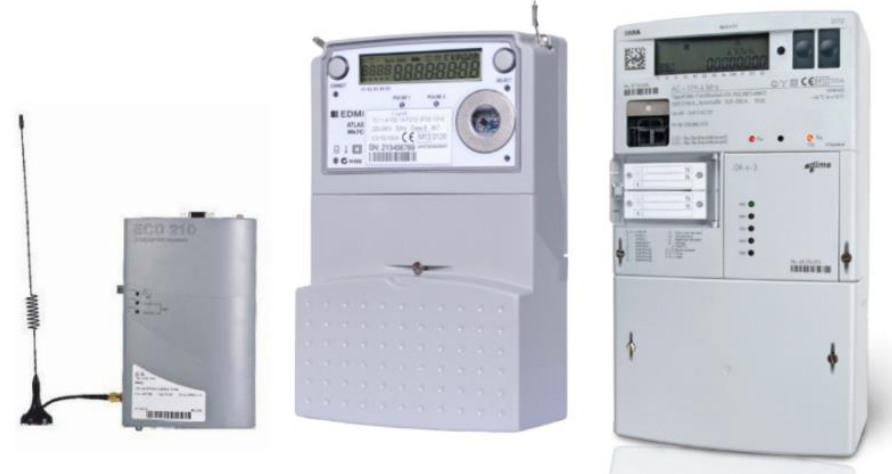

Fig. 32. Automated meter reading used for CRT tariffs.

Smart metering system plays a vital role in the operation of the power system of Oman. Recently, the distribution companies are expanding the use of smart meters for all categories of customers, especially for residential customers. There are several benefits for using smart meters in the distribution system as summarized [52]:

$>$ improve the accuracy of meter reading

$>$ enhance the billing system

$>$ improved security for premises

$>$ prevents meter tampering.

$>$ provide the ability for analysis and useful interpretation of usage trends.

$>$ customer satisfaction.

$>$ accuracy in tracking the demand.

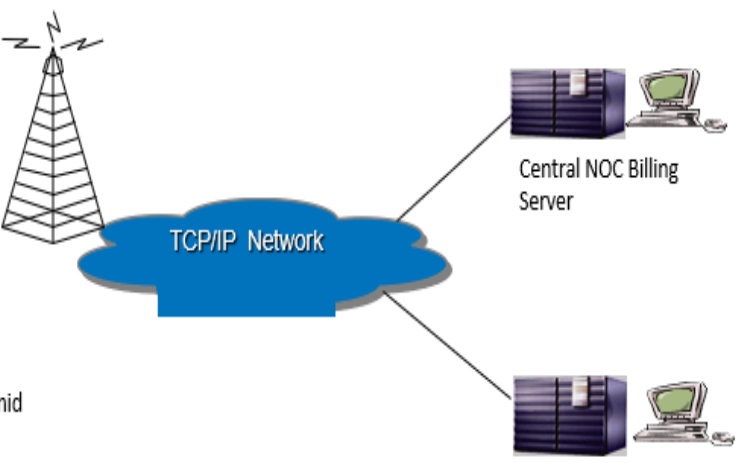

Disaster Recovery Site

Fig. 33. Automatic meter reading scheme. 
The automatic meter reading depends on three technologies which are Public Switched Telephone Network (PSTN/Landline) based AMR, Radio frequency-based AMR and PLCC based AMR. PSTN/Landline based AMR uses telephone infrastructure for meter reading and radio frequency-based AMR uses radio frequency networks. On the other hand, Power Line Carrier Communication (PLCC) based AMR uses the transmission power line as a channel to transfer the reading signals to the central data processing terminal. AMR scheme is shown in the Fig. 33, using CodeDivision Multiple Access (cCDMA) network technology to collect data from the meter as per programmed schedule/on demand with meter-dependent commands, and uploads to billing servers using standard based Transmission Control Protocol (TCP)/Internet Protocol (IP).

\section{Conclusion}

This paper analyzed current power situation in the Sultanate of Oman and the possibilities of integration smart grid technologies. The power system of Oman consists of four separated networks: Main Interconnected System (MIS), Dhofar Power System (DPS), Musandam power system and AD DUQM power system. The various types of operation with regards to generation, transmission and distribution in these isolated networks were discussed in details considering their capacities. The potentials of solar energy in Oman were emphasized regarding its availability in tremendous amounts at various parts of the country, due to its geographical location as well as the ratio of sky clearance, which is 342 days per year. In addition, the wind speed data indicated that the average wind speed at $10 \mathrm{~m}$ is around $5.7 \mathrm{~m} / \mathrm{s}$, considering different locations which also provide high potential evidence for setting up wind energy projects. On the other hand, regarding the renewable energy integration, it was mentioned that in order to integrate any renewable energy sources in existing electrical power distribution and transmission system, both planning and operational analysis should be considered. There are several new technologies that should be considered in the designing and upgrading of the Omani power system to maintain smart, reliable and flexible system. These are a remote controlling and operation system that involves smart metering as well as using solar and wind energy to enhance the power system integrity. Finally, the power sector in Oman could be enhanced through the use of smart grid technologies by the operation and control of the load dispatch centers and extended use of smart meters for distribution companies and their clients.

\section{References}

[1] IRENA, "Renewable Energy Market Analysis: GCC 2019”, International Renewable Energy Agency (IRENA), Abu Dhabi, 2019.

[2] IRENA, "Renewable Energy Market Analysis: GCC Region, International Renewable Energy Agency, 2020.

[3] R. Ferroukhi, N. Ghazal-Aswad, S. Androulaki, D. Hawila and T. Mezher, "Renewable energy in the GCC:status and challenges", International Journal of
Energy Sector Management, vol.7, no.1, pp. 84-112, 2020.

[4] A. Hepbasli, and Z. Alsuhaibani, "A key review on present status and future directions ofsolar energy studies and applications in Saudi Arabia", Renewable and Sustainable EnergyReviews, vol. 15 no. 9, pp. 5021-50, 2011.

[5] M. Abdalla, A. Imad, "Development of renewable energy in the GCC region: status and challenges" International Journal of Energy Sector Management, vol. 14, no. 6, pp. 1049-1071, 2020.

[6] World Bank Population Report, 2019.

[7] Oman Electricity and Transmission Company, Annual Report, 2018.

[8] N. Hosseinzadeh, M. Albadi, A. AlHinai, A. AlBadi, S. Islam, "Customized Pathway for Smart Grid Development- A case of Oman", IEEE Innovative Smart Grid Technologies Asia (ISGT-Asia), pp. 553-558, Melbourne, Australia, Nov 28 - Dec 1, 2016.

[9] Oman Power and Water Procurement Company, OPWP 7 Year Statement 2019 - 2025. Muscat Office, 2020.

[10] S. M. Arif, Malik, M. Bouzguenda, "Effects of smart grid technologies on capacity and energy savings: A case study of Oman”, Energy, vol. 54, pp. 365-371 2013.

[11] A. Al-Badi, A. Malik, K. Al-Areimi, A. Al-Mamari, "Power sector of Oman today and tomorrow", Renewable and Sustainable Energy Reviews", vol, 13, 2192-2196, 2009.

[12] A. Malik, M. Bouzguenda, "Smart grid capacity and energy saving potential-a case study of Oman". In: IEEE PES ISGT Middle East Conference, Jeddah 17-20 December 2011.

[13] United Nations Annual Report, 2020.

[14] M. Albadi, A. Al Badi, R. Ghobani, A. Al Hinai, R. Al Abri, "Enhancing electricity supply mix in Oman with energy storage systems: a case study", International Journal of Sustainable Engineering, 2020. https://doi.org/10.1080/19397038.2020.1773570

[15] B. Emiliano, PV Magazine available at: Oman reveals final bidders of $500 \mathrm{MW}$ solar tender - PV magazine International (pv-magazine.com).

[16] K. E. Okedu, A. Al Senaidi, A. Al Senaidi, A. Al Senaidi, and Waleed Al Salmani, "Real Time Dynamic Analysis of Solar PV Integration for Energy Optimization", International Journal of Smart Grid, vol.4, no. 2, pp. 68-79, June, 2020.

[17] K. E. Okedu, and M. Al-Hashmi, "Assessment of the Cost of various Renewable Energy Systems to Provide Power for a Small Community: Case of Bukha, Oman", International Journal of Smart Grid, vol.2, no. 3, pp. 172182, 2018.

[18] R. P. Praveen, V. Keloth, A. Abo-Khalil, G. Ahmed, A. Ali, A. M. Eltamaly, T. Iskander, "An insight to the energy policy of GCC countries to meet renewable energy targets of 2030", Energy Policy, vol. 147, 111864, 2020.

[19] Annual Report of the Authority for Electricity Regulations (AER), Sultanate of Oman, 2017.

[20] The Renewables Readiness Assessment (RRA) conducted in the Sultanate of Oman, International Renewable Energy Agency (IRENA), 2014. 
[21] Council of Financial Affairs and Energy Resources in Oman, 2018.

[22] Oman Electricity and Transmission Company, Annual Report, 2019.

[23] A. H. Al-Badi, R. Ahshan, N. Hosseinzadeh, R. Ghorbani and E. Hossain, 'Survey of smart grid concepts and technological demonstrations worldwide emphasizing on the Oman perspective', Applied System Innovation, vol. 3, no. 1, pp. 1-27, 2020.

[24] E. Hossain, I. Khan, F. Un-noor, S. S Sikander, M. S. Sunny 'Application of Big Data and Machine Learning in Smart Grid, and Associated Security Concerns: A Review', IEEE Access, 7, pp. 13960-13988, 2019.

[25] Mazoon Electricity Company of Oman, 2018.

[26] Oman Electricity Transmission Company, Annual Report, Five-Year Annual Transmission Capability Statement Muscat Office, OETC, 2017.

[27] I. S. Bayram, and H. Mohsenian-Rad, "An overview of smart grids in the GCC region", Lecture Notes of the Institute for Computer Sciences, Social-Informatics and Telecommunications Engineering, LNICST, 166 (October 2016), pp. 301-313. doi: 10.1007/978-3-31933681-7_25.

[28] Sultanate of Oman, Oman Power and Water Procurement Company, 2019.

[29] A. Al-Badi, and S. Hasan, "Oman Electricity Sector: Features, Challenges and Opportunities for Market Integration", [e-journal]. p. 3-7.

[30] A.H AlBadi, M. H. Albadi, A. Malik, M. Al-Hilahi, A. Al-Busaidi, and Al-Omairi, "Levelised electricity cost for wind and PV-diesl hybrid system in Oman at selected sites", International Journal of sustainable energy, vol. 2, no. 2, pp. 223-235, 2013.

[31] A.H. Al-Badi, M. H. Al-Badi, A. M. Al-lawati and A.S. Malik, "Economic Perspective of PV electricity in Oman”, Energy, vol. 36, no. 2, pp. 226-232, 2011.

[32] K. E. Okedu, and Waleed Z. AL Salmani, "Smart Grid Technologies in Gulf Cooperation Council Countries: Challenges and Opportunities", International Journal of Smart Grid, vol.3, no. 2, pp. 92-102, June, 2019.

[33] Authority for Electricity Regulation in Oman, 2008.

[34] K. E. Okedu, Husam AL Nadabi, Ahmed Aziz, "Prospects of Solar Energy in Oman: Case of Oil and Gas Industries", International Journal of Smart Grid, vol.3, no. 3, pp. 138-151, September, 2019.

[35] Petroluem Development Company of Oman, Annual Report, 2018.

[36] O. N. Agancy, Geographic-Location - Sultanate of Oman, 2019. [Online]

Available at: https://omannews.gov.om/GeographicLocation [Accessed 2nd December 2020].

[37] A. AlBadi, "Wind Power Potential in Oman", International Journal of Sustainable Energy, vol. 30, no. 2, pp. 110-118, 2010.
[38] Meteorology, D. G. O., 2020. Historical Data. [Online] Available at:

http://www.met.gov.om/opencms/export/sites/default/dg man/en/weather-chart/historical-data/index.html [Accessed 2nd December 2020].

[39] WorldOMeter, 2020. WorldOMeter. [Online] Available at: https://www.worldometers.info/worldpopulation/omanpopulation/\#: :text=Oman\%20population $\% 20$ is $\% 20$ equi valent\%20to,43\%20people\%20per\%20mi2).

[Accessed 2nd December 2020].

[40] Office of electricity. Power system Integartion.

[Online]. Available from:

https://www.energy.gov/oe/services/technologydevelopment. [Accessed: 5th June 2012].

[41] R. Ferroukhi, and N. Ghazal-Aswad, S. Androulaki, D. Hawila, T. Mezher, "Renewable energy in the GCC: status and challenges", [e-journal]. p. 84-112, 2013.

[42] H. Al Riyami, A. Al Busaidi, A. Al Nadabi, "Integration of 50MW Dhofar Wind Farm Intermittency in System Planning \& Operation", [e-journal]. p. 22-30.

[43] S. Sundararagavan, E. Baker, "Evaluating energy storage technologies for wind power integration", Solar Energy, vol. 86, pp. 2707-2717, 2012.

[44] R. Ahshan, A. Al-Badi, A., H. Hosseinzadeh, Survey of Smart Grid Concepts and Technological Demonstrations Worldwide Emphasizing on the Oman Perspective. [e-journal]. p. 9-20, 2020.

[45] GTR, 2020. Global Transmission. [Online] Available at: https://www.globaltransmission.info/archive.php?id=389 $\underline{60}$ [Accessed 5th December 2020].

[46] OETC, Load Dispatch Center, 2020.

[47] OETC, Transmission Capability Statement, Muscat: OETC, 2020.

[48] Power, A., 2019. Ibri-2 PV (IPP). [Online]

[49] H. Shahid, T. Al-Aqeel, Y. Bhatt, "Oman Electricity Sector: Features, Challenges and Opportunities for Market Integration", Riyadh: The King Abdullah Petroleum Studies and Research Center (KAPSARC), 2019.

[50] M B Control \& Systems Pvt Ltd. [Online] Available at: https://www.mbcontrol.com/scada-energymanagement-solution/ [Accessed 2nd December 2020].

[51] F. Al-Tobi, Oman Grid-Half Yearly bulletin, Muscat: Oman Electricity Transmission Company OETC, 2018.

[52] Muscat Electricity Distribution Company, Cost Refrective Tariff CRT, Muscat: MEDC, 2019.

[53] Authority for Public Service Regulation, PERMITTED TARIFFS, 2020. [Online] Available at: https://www.apsr.om/en/tariffs [Accessed 2 December 2020]. 